\title{
A comparison Between the Effects of Shape Memory Alloys and Carbon Nanotubes on the Thermal Buckling of Laminated Composite Beams
}

\author{
Saeed Kamarian $^{\mathrm{a}}$, Mahdi Bodaghi ${ }^{\mathrm{b}}$, Reza Barbaz Isfahani ${ }^{\mathrm{c}}$, Jung-il Song $^{\mathrm{a}}{ }^{\dagger}$ \\ a. Department of Mechanical Engineering, Changwon National University, Changwon, South Korea \\ b. Department of Engineering, School of Science and Technology, Nottingham Trent University, Nottingham, NG11 8NS, United Kingdom \\ c. Department of Mechanical Engineering, Amirkabir University of Technology, Tehran, Iran
}

\begin{abstract}
One of the essentials for designing composite structures exposed to heat is the correct choice of reinforcing materials. In the present research work, a comparison is made between the performances of two well-known advanced materials, Shape Memory Alloys (SMAs) and Carbon Nanotubes (CNTs), in thermal bucking behavior of thin composite beams with simply supported boundary conditions. First, the effect of embedding SMA wires on the thermal buckling of laminated composite beams are examined. The stability equations are derived based on Timoshenko Beam Theory (TBT), and the critical buckling temperatures are obtained analytically. The advantages and disadvantages of using SMA wires as well as their proper functional range are studied. Then, in the next step, the influence of CNTs on the thermal buckling response of composite beams is presented. To this end, the results of some experiments such as Dynamic Mechanical Thermal Analysis (DMTA) and Thermo-Mechanical Analysis (TMA) tests are used to obtain thermal properties of CNT-reinforced composite materials. The performance of CNTs is also evaluated in comparison with SMA wires. It is found from the analysis that, depending on the structural conditions, one reinforcing material can outperform the other. Finally, the idea of simultaneous use of both reinforcing materials comes up. The results show that, in some circumstances, the use of only one of the SMAs or CNTs does not have significant effect on the thermal buckling of composite beams, but applying both of these advanced reinforcing materials in the composite medium can extraordinarily enhance the critical buckling temperatures.
\end{abstract}

Keywords: Composite Beams; Thermal Buckling; Advanced Materials; Shape Memory Alloys; Carbon Nanotubes

\footnotetext{
${ }^{\dagger}$ Corresponding Author, E-mail: jisong@changwon.ac.kr
} 


\section{Introduction}

Today, composite materials are used in most engineering structures, especially in automotive, marine and aerospace industries. In some cases, these composites are exposed to thermal environments. Under such conditions, compressive thermal stresses may be produced which can have a significant impact on the structural stiffness. The generated thermal stresses deteriorate the stiffness of structures and may cause buckling phenomenon in them (Bouazza, Benseddiq, and Zenkour 2019; Jermsittiparsert et al. 2020; Miglani, Devarajan, and Kapania 2018; Panda and Singh 2013; Shiau and Kuo 2004; Van, Nguyen, and Lee 2019; Zhang, Pan and Chen 2019). To reduce the damaging effects of thermal stresses on composite structures, researchers often propose to use new and advanced reinforcing materials. Therefore, selecting a suitable reinforcing material is of great importance.

One of the advanced materials which can cope with thermal buckling in composite structures is SMAs that have been widely used for different applications during the last decade (Abid et al. 2019; Guida et al. 2019; Jhou et al. 2018; Nasakina et al. 2015). SMAs are referred to a set of alloys that are capable of recovering the permanent deformations and strains applied to them and eventually returning to their original form. One application of SMAs is that they are first prepared as pre-strained wires and then embedded into a composite structure exposed to heat. When the composite is heated, pre-strained SMA wires are prevented from recovering their initial strains. This makes them to produce a large tensile recovery stress due to a phase transformation which can compensate for some of the generated thermal stresses. Therefore, in most cases, the stiffness of the structures increases and its critical buckling temperature is delayed. Some researchers have shown that the recovery stress of SMAs may have a significant influence on the structural stability and thermal buckling of composite components such as beams, plates and shells (Asadi et al. 2013a; Asadi et al. 2014a; Kamarian and Shakeri 2017; Salim et al. 2018). Among those focused on composite beams, Asadi et al. (2013b) studied large amplitude vibration and thermal buckling of laminated composite beams with embedded SMA wires for different boundary conditions. They applied Brinson model for thermo-mechanical constitutive equation of SMAs to calculate the recovery stress produced in the structure. The governing equations were derived based on the Classical Beam Theory (CBT) with von Kármán-type non-linearity. Then, by implementing Galerkin method, a closed-form solution was obtained for thermal post-buckling and free vibration of the composite beam. From this study, it was concluded that embedding SMA wires into composite beams can significantly increase the critical buckling temperature and decrease the post-buckling deflection. Asadi et al. (2014b) investigated non-linear thermal stability of SMA/graphite hybrid composite Timoshenko beams. They showed that volume fraction and pre-strain of SMA wires have dramatic effects on the buckling behavior of laminated beams. Abdollahi et al Asadi et al. (2015) examined 
non-linear stability of SMA/graphite hybrid laminated composite beams resting on non-linear hardening elastic foundation. The governing equations were obtained based on TBT and by using virtual work principles. Then, the equations were solved by applying GDQ technique for various types of boundary conditions and different lamination schemes. Numerical results revealed that embedding SMA wires can lead to a sharp change on pre-buckling and post-buckling behaviors of laminated composite beams. Bayat and Ekhteraei Toussi (2017) found an exact solution for thermal buckling and post buckling of SMA hybrid laminated composite beams based on layer wise theory. They used one dimensional Brinson theory for estimation of thermo-mechanical properties of SMA wires. A parametric study was comprehensively done to illustrate the influence of some parameters like stacking sequence of layers, thickness to span ratio, degree of anisotropy, volume fraction and pre-strain of SMAs on the buckling characteristics of composite beams.

Along with the remarkable and effective properties of SMAs, it should be noted that the use of this reinforcing material has some problems. For example, in order to produce tensile recovery stress, SMA wires should be exposed to temperatures above austenite start temperature. Therefore, depending on the intended purpose, they may not have much impact on the structure at low temperatures. Another important point is that if the host material properties like stiffness, strength and toughness are too different from those of the wires, incompatibilities may occur such as premature delamination of the wire, early failure of the structure or the impossibility to sustain temperature differences due to large differences in thermal expansion (Cohades and Michaud 2018). Also, a negative coefficient of thermal expansion of the host in the SMA wires direction will favor the negative strain needed for active damping or shape morphing. On the other hands, depending on the given application and required properties, the choice of an appropriate host composite is limited. As a result, some modification should be considered. One more example for limitations of using SMAs is that utilizing shape memory wires usually makes the structure heavier which may have a negative impact on the vibrations of structures at low temperatures. Therefore, a solution should be found to minimize the disadvantages of SMAs or reduce the need to use them in composite structures. The proposed option in the present research work is to utilize CNTs with unique properties such as lightness, high strength, dispersion uniformity, wear resistance and ease of implementation.

CNTs have attracted the attention of many researchers in recent years. Due to their unique characteristics, CNTs have been widely used in engineering structures. Over last decade, there has been a great deal of research to investigate the influence of CNTs on mechanical, thermal and electrical properties of polymers showing that only a small amount of this material, often less than 0.5 weight-percent (wt. \%), can have a significant improvement for the composite properties (He et al. 2018; Kamarian et al. 2019; Maghsoudlou 
et al. 2019; Rahman et al. 2012a ; Zhu et al. 2004). Siddiqui et al. (2009) showed that 0.3 wt.\% CNT-epoxy nanocomposite coating could lead to a significant increase in tensile strength of the single fiber for all gauge lengths, better than the neat epoxy coating. Barai and Weng (2011) revealed experimentally and numerically that CNT agglomeration and imperfect interface condition can seriously reduce the effective stiffness and elasto-plastic strength. Thermo-mechanical influence of incorporating a uniformly dispersed multi-walled carbon nanotubes (MWCNTs) into the pristine and polyol-toughened epoxy was studied by Rahman et al. (2012b). They showed that adding 0.3 wt.\% MWCNTs could enhance the composite stiffness while reduce Coefficient of Thermal Expansion (CTE) lower than CTE of epoxy-based resins. Though, there has been a lot of research investigating the effect of CNTs on the buckling of beams under thermal environments (Ebrahimi and Farazmandnia 2018; Song et al. 2019 ; Wu, Kitipornchai, and Yang 2017), to the best of authors' knowledge, almost all of these structures consist of only pure polymers reinforced by functionally graded nanotubes or graphene, and their thermo-mechanical properties are estimated by the rule of mixture model with some limitations. However, in common engineering applications, composite structures usually include long and continuous fibres, such as carbon fibres or glass fibres. Also, the research performed by the authors has shown that rule of mixture is not proper to estimate the CTE of polymers reinforced by CNTs and may cause a relatively large error in the results (Kamarian et al. 2019).

Due to the limitations of using SMA wires and CNTs, as well as due to the lack of research on the use of these smart materials to improve thermal buckling of composite beams according to the real conditions, the present work follows three main goals. First, the effect of SMA wires on the buckling of laminated composite beams is investigated. To this end, thermo-mechanical properties of the wires are obtained based on one-dimensional Brinson model. The governing equations are derived based on TBT. These equations are then solved analytically and a closed-form solution is provided for simply supported boundary conditions. It is worth noting that one of the important factors for implementation of composite structures is glass transition temperature $\left(T_{g}\right)$ so that the operating temperature has to be less than this temperature. Although this temperature is very crucial, only few research works have considered it as a limiting factor in thermal buckling analysis of composite structures (Jin et al. 2015; Liu et al. 2006 ; Shi et al. 2014). Unlike previous research works, the emphasis here is on finding the appropriate functional range of SMAs in terms of geometrical parameters due to the limitation of the working temperature of the structure such as $T_{g}$ which is determined by the use of DMTA. The advantages and disadvantages of using SMA wires as a reinforcing phase in composite beams are also comprehensively discussed. As the second purpose of this study, the influence of CNTs on the critical buckling temperature of composite beams is presented. The mechanical properties of the nanocomposite beam can appropriately be obtained using existing theoretical models, but 
there is no proper developed model to predict the CTE of nanotube-reinforced polymers. Therefore, the CTE of MWCNT-reinforced epoxy is obtained experimentally, and then the total thermo-mechanical properties of CNT/graphite fiber/epoxy beam can be predicted using existing micromechanical models. Like SMAs, useful features as well as limitations of CNT utilization are mentioned. Finally, the idea of using composite beams reinforced by hybrid advanced materials (both SMAs and CNTs) is presented here, as the main idea of the present work, in order to overcome the drawbacks and disadvantages of any of the mentioned materials. The reason is that by having the unique properties of these smart materials simultaneously, the performance of composite beams is improved, the material consumption is saved, and the weight of structure is reduced. The results of present study indicate that by forming a composite beam with hybrid advanced reinforcing materials, thermal buckling of composite structures enhances at all operating temperature and all geometrical parameters.

\section{Problem description}

When a constrained orthotropic composite structure is applied in a thermal environment, thermal stresses may generate in it, which are generally obtained from the following relation.

$$
\{\sigma\}=[\bar{Q}](\{\varepsilon\}-\Delta T\{\alpha\})
$$

where $\{\sigma\},\{\varepsilon\},\{\alpha\},[\bar{Q}]$ and $\Delta T$ denote the stress vector, strain vector, thermal expansion coefficient vector, stiffness matrix, and variation of temperature, respectively. It is observed that with the increase of temperature, the induced thermal stresses increase. These thermal stresses, depending on the lamination scheme and boundary conditions, may lead to buckling phenomenon which should be prevented. There are three general ways to deal with these destructive thermal stresses. The first suggestion is to use some materials to produce tensile stress to compensate for some of the compressive thermal stresses. The idea of using shape memory wires falls into this category.

$$
\{\sigma\}=[\bar{Q}](\{\varepsilon\}-\Delta T\{\alpha\})+\left\{\sigma^{S M A}\right\}
$$

The second way is to utilize some additives to improve thermo-mechanical properties of the materials. The idea of using CNTs can be classified in this category.

$$
\{\sigma\}=[\bar{Q}]_{\text {new }}\left(\{\varepsilon\}-\Delta T\{\alpha\}_{\text {new }}\right)
$$

The final way is to optimize the stacking sequence of layers in order to yield best total stiffness of structure. 


$$
\{\sigma\}=[\bar{Q}]_{\text {optimum }}(\{\varepsilon\}-\Delta T\{\alpha\})
$$

As mentioned in Introduction section, in the present work, the first two approaches (using SMA wires and CNTs) are examined and compared to each other. In the first step, shape memory wires are embedded in the composite medium to produce tensile recovery stress in the structure. Then, in the second step, CNTs are added to the epoxy to form a new polymer matrix with better material properties. Finally, both reinforcing materials, SMA wires and CNTs, are used in the structure to form a hybrid composite with new material properties and tensile recovery stress.

$$
\{\sigma\}=[Q]_{\text {new }}\left(\{\varepsilon\}-\Delta T\{\alpha\}_{\text {new }}\right)+\left\{\sigma^{S M A}\right\}
$$

\subsection{Base composite beam}

Consider a laminated composite beam, as shown in Fig. 1. The beam is made of epoxy and long graphite fibers and assumed to be under thermal environment with uniform temperature distribution. LY-5052 epoxy, purchased from Huntsman Corporation, is considered here as the resin. According to the data sheet of the manufacturer, the Young modulus and Poisson's ratio of the epoxy are 3.1GPa and 0.35, respectively. One of the most important parameters which must be considered for polymer-based composites under thermal environments is the glass transition temperature. This parameter specifies the operating temperature range so that at temperatures above $T_{g}$, the structure loses its thermo-mechanical properties. Thus, here, DMTA test was carried out on the samples $40 \mathrm{~mm} \times 10 \mathrm{~mm} \times 3 \mathrm{~mm}$ in an axial tensile way with frequency of force oscillation $1 \mathrm{~Hz}$ and heating rate $5^{\circ} \mathrm{C} / \mathrm{min}$ ranging from 25 to $200^{\circ} \mathrm{C}$. The experimental indicated that $T_{g}=112.5^{\circ} \mathrm{C}$. The CTE of the polymer was also considered in accordance with ASTM E831 standard. Based on this standard. After conducting TMA, the average of CTE is calculated which is $66 \times 10^{-6} /{ }^{\circ} \mathrm{C}$. Table 1 shows the thermo-mechanical properties of epoxy LY5052 implemented in the present work. The material properties of long graphite fibers are also provided in Table 2. Therefore, using available micro-mechanical models (See Appendix 1), the thermo-mechanical characteristics of the graphite fiber/ epoxy composite beam can be calculated which are shown in Table 3. It should be mentioned that the volume fraction of long fibers are assumed to be $55 \%$ in the present work.

\subsection{Shape memory alloys}


The extraordinary characteristics of SMAs is due to the transformation of parent phase called austenite ( $A$ ) to martensite ( $M$ ) phase and vice versa under thermo-mechanical loading. Fig. 2 shows that depending on the amount and type of loads applied to the SMAs, two different twinned and detwinned martensite variants, and austenite phase can develop. In this figure, $M_{s}, M_{f}, A_{s}$ and $A_{f}$ indicate "martensite start", "martensite finish", "austenite start" and "austenite finish" temperatures, respectively, in the absence of stress. $\sigma_{s}^{c r}$ and $\sigma_{f}^{c r}$ also denote critical stress values for start and finish of conversion of twinned martensite to detwinned martensite below $M_{s}$ which are presumed to be constant. For $T>M_{s}$, these stresses vary almost linearly versus temperature. In Fig. 2, the slope of curves $\left(C_{A}\right.$ and $\left.C_{M}\right)$ are presumed to be constant and considered as material features of shape memory wires (Brinson 1993). Here, the recovery stress of SMA wires is calculated based on the simplified form of the Brinson model (Brinson and Huang 1996) in which the martensite volume fraction $\xi$ is separated into stress-induced $\xi_{s}$ and temperature-induced components $\xi_{\mathrm{T}}$.

$$
\xi=\xi_{s}+\xi_{\mathrm{T}}
$$

Based on the simplified Brinson model, the recovery stress can be calculated in the following form:

$$
\sigma=E_{s}(\xi)\left(\varepsilon-\varepsilon_{L} \xi_{s}\right)+\Theta \Delta T
$$

where $\varepsilon_{L}$ denotes the maximum residual strain, $\Theta$ represents thermal expansion coefficient of SMAs, $\Delta T$ is temperature variations, and $E_{s}$ refers to Young's modulus of SMA wires expressed based on the Reuss model as :

$$
E_{s}(\xi)=\frac{E_{A}}{1+\left(\frac{E_{A}}{E_{M}}-1\right) \xi}
$$

in which, $E_{A}$ and $E_{M}$ are defined as Young's modulus of the SMA in the pure austenite and pure martensite phases, respectively. According to Brinson (1993), martensite fractions during heating stage when $T>A_{s}$ and $C_{A}\left(T-A_{f}\right)<\sigma<C_{A}\left(T-A_{s}\right)$ can be calculated as:

$$
\begin{aligned}
& \xi=\frac{\xi_{0}}{2}\left\{\cos \left[\frac{\pi}{A_{f}-A_{s}}\left(T-A_{s}-\frac{\sigma}{C_{A}}\right)\right]+1\right\} \\
& \xi_{s}=\xi_{s 0} \frac{\xi}{\xi_{0}} \quad, \quad \xi_{T}=\xi_{T 0} \frac{\xi}{\xi_{0}}
\end{aligned}
$$


where the subscript ' 0 ' represents the initial state of a parameter. Since the martensite fraction depends on the stress and temperature, Eq. (7) must be coupled with equation (9) to formulate a complete governing equation for SMAs. The material properties of implemented SMA wires in the present work are shown in Table 4. More details about SMAs and their behavior can be found in the research works performed by Brinson (1993) and Brinson and Huang (1996).

\subsection{Carbon nanotubes}

As mentioned earlier, many research studies have shown that only small amount of CNTs can have significant influence on the thermo-mechanical properties of polymers. In the present study, the role of adding 0.3 wt.\% MWCNTs, produced by the US Research Nanomaterials, in enhancing material properties of LY-5052 epoxy is investigated (Kamarian et al. 2019). The material features of CNTs can be observed from Table 5. Having some material properties of epoxy and CNT, it is possible to calculate the Young modulus of CNT-reinforced epoxy polymer with acceptable accuracy as follows (Qian et al. 2000):

$$
\begin{aligned}
& E_{N C}=\left[\frac{3}{8} \frac{1+2\left(l_{N T} / d_{N T}\right) \eta_{L} V_{N T}}{1-\eta_{L} V_{N T}}+\frac{5}{8} \frac{1+2 \eta_{T} V_{N T}}{1-\eta_{T} V_{N T}}\right] E_{P} \\
& \eta_{L}=\frac{\left(E_{N T} / E_{P}\right)-1}{\left(E_{N T} / E_{P}\right)+2\left(l_{N T} / d_{N T}\right)} \\
& \eta_{T}=\frac{\left(E_{N T} / E_{P}\right)-1}{\left(E_{N T} / E_{P}\right)+2}
\end{aligned}
$$

where $E_{P}$ and $E_{N T}$ denote Young's modulus of the epoxy and nanotubes, respectively. $l_{N T}, d_{N T}$ and $V_{N T}$ also represent the length, the outer diameter and the volume fraction of MWCNTs.

Like pure epoxy, the $T_{g}$ of the nanocomposite polymer were obtained using DMTA experimental test. In many studies, it has been shown that by adding CNTs to the polymer, $T_{g}$ rises, but it should be noted that this is not always the case. Aïssa and Bounia (2009) pointed out that depending on the type and amount of CNTs, the nanocomposite glass transition temperature can decrease or increase or even remain unchanged. Therefore, by conducting a test on the nanocomposite with $0.3 \mathrm{wt} \%$ of MWCNTs, its glass transition temperature was measured. To this end, first, the nanocomposite specimens were provided by following the steps in Fig. 3. DMTA experimental results showed that $T_{g}=110.5^{\circ} \mathrm{C}$ for CNT-reinforced epoxy. It means that increasing the wt. $\%$ of MWCNTs from 0 to 0.3 reduces the glass transition temperature as much as $2{ }^{\circ} \mathrm{C}$. Also, based on the previous study of the authors (Kamarian et al. 2019), the experimental 
data showed that the average CTE of nanocomposite polymer was about $44 \times 10^{-6} /^{\circ} \mathrm{C}, 33 \%$ less than the pure epoxy. Thus, it can be concluded that CNTs can dramatically decrease the value of CTE for the epoxy polymer which can play an important role in structural response in thermal environments. In association with Poisson's ratio, it should be noted that its value is assumed to be constant. In this regard, Spanos and Kontsos (2008) showed that CNTs do not affect the Poisson's ratio of polymers by a considerable amount. Table 6 indicates thermo-mechanical properties of the epoxy polymer reinforced by $0.3 \mathrm{wt} \%$ nanotubes. Employing rule of mixture, the material properties of graphite fiber/CNT/epoxy can be calculated which are shown in Table 7.

\section{Formulation}

\subsection{Equilibrium equations}

Consider the laminated composite beam with length of $L$ and thickness of $h$, as shown in Fig. 1. Based on TBT, the axial and lateral displacements of a typical point $P(x, z)$ can be expressed by $u$ and $v$ as (Reddy 2003):

$$
\begin{aligned}
& \bar{u}(x, z)=u(x)+z \varphi(x) \\
& \bar{w}(x, z)=w(x)
\end{aligned}
$$

where $\varphi$ is the rotation of the beam cross-section. The axial and shear strains associated with the displacements are given in the following form:

$$
\begin{aligned}
& \varepsilon_{x x}=\frac{\partial \bar{u}}{\partial x}+\frac{1}{2}\left(\frac{\partial \bar{w}}{\partial x}\right)^{2}=\frac{d u}{d x}+\frac{1}{2}\left(\frac{d w}{d x}\right)^{2}+z \frac{d \varphi}{d x} \\
& \gamma_{x z}=\frac{\partial \bar{u}}{\partial z}+\frac{\partial \bar{w}}{\partial x}=\varphi+\frac{d w}{d x}
\end{aligned}
$$

The constitutive law for the $k t h$ layer of a SMA-reinforced composite beam can be expressed as follows:

$$
\begin{aligned}
& \sigma_{x}^{k}=\bar{Q}_{11}^{k}\left(\varepsilon_{x}^{k}-\alpha_{x}^{k} \Delta T\right)+\cos ^{2}\left(\theta^{k}\right) V_{s}^{k} \sigma_{r}^{k} \\
& \tau_{x z}^{k}=\bar{Q}_{55}^{k} \gamma_{x z}^{k}
\end{aligned}
$$

where $\bar{Q}_{i j}$ denote the transformed reduced stiffness coefficients, the details of which are in Appendix 2, $\theta$ refers the orientation of fibers and SMA wires with the assumption that they are aligned (Tsoi et al. 2003), $\Delta T$ is the temperature variation, and $\alpha_{x}$ represents the thermal expansion coefficient defined as: 


$$
\alpha_{x}=\cos ^{2}(\theta) \alpha_{1}+\sin ^{2}(\theta) \alpha_{2}
$$

in which $\alpha_{1}$ and $\alpha_{2}$ denote the longitudinal and transverse thermal expansion coefficients, respectively.

Furthermore, $V_{s}$ is the volume fraction of SMA wires, and $\sigma_{r}$ denotes the recovery stress generated by pre-strained SMA wires, as described in subsection 2.2.

Based on the principle of virtual work, in the absence of external loads, we have the following expression:

$$
\delta U=0
$$

where $U$ is the strain energy defined as:

$$
U=\int_{A}^{h / 2} \int_{-h / 2}\left(\sigma_{x} \varepsilon_{x}+k_{s} \tau_{x z} \gamma_{x z}\right) d z d A
$$

where $k_{s}$ is the shear correction factor taken as 5/6. By combining Eqs. (12) - (16) the following equilibrium equations can be obtained.

$$
\begin{aligned}
& \frac{d N_{x}}{d x}=0 \\
& \frac{d Q_{x z}}{d x}+\frac{d}{d x}\left(N_{x} \frac{d w}{d x}\right)=0 \\
& \frac{d M_{x}}{d x}-Q_{x z}=0
\end{aligned}
$$

The boundary conditions at the edges can be also obtained as follows:

$$
\left\{\begin{array}{l}
\text { either } u=0 \text { or } N_{x}=0 \\
\text { either } \varphi=0 \text { or } M_{x}=0 \\
\text { either } w=0 \text { or } Q_{x}+N_{x} \partial w / \partial x=0
\end{array}\right.
$$

in which $N_{x}, M_{x}$ and $Q_{x z}$ are the stress resultants defined as follows:

$$
\begin{aligned}
& N_{x}=\int_{-h / 2}^{h / 2} \sigma_{x} \mathrm{~d} z=A_{11}\left(\frac{d u}{d x}+\frac{1}{2}\left(\frac{d w}{d x}\right)^{2}\right)+B_{11} \frac{d \varphi}{d x}-N^{T}+N^{r} \\
& M_{x}=\int_{-h / 2}^{h / 2} z \sigma_{x} \mathrm{~d} z=B_{11}\left(\frac{d u}{d x}+\frac{1}{2}\left(\frac{d w}{d x}\right)^{2}\right)+D_{11} \frac{d \varphi}{d x}-M^{T}+M^{r} \\
& Q_{x z}=\int_{-h / 2}^{h / 2} k_{s} \tau_{x z} \mathrm{~d} z=A_{55}\left(\varphi+\frac{d w}{d x}\right)
\end{aligned}
$$


where $N_{x}^{T}$ and $M_{x}^{T}$ denote the induced thermal force and moment, and $N_{x}^{r}$ and $M_{x}^{r}$ represent the inplane force and moment generated by shape memory wires. Furthermore, $A_{11}, B_{11}, D_{11}$ and $A_{55}$ are the extensional, bending-extension, bending, and transverse shear stiffness coefficients.

$$
\begin{aligned}
& \left(N^{T}, M^{T}\right)=\sum_{k=1}^{N L} \int_{z_{k-1}}^{z_{k}} \bar{Q}_{11}^{k} \alpha_{x}^{k} \Delta T(1, z) \mathrm{d} z \\
& \left(N^{r}, M^{r}\right)=\sum_{k=1}^{N L} \int_{z_{k-1}}^{z_{k}} \sigma_{r}^{k} V s \cos ^{2}\left(\theta^{k}\right)(1, z) \mathrm{d} z \\
& \left(A_{11}, B_{11}, D_{11}\right)=\sum_{k=1}^{N L} \int_{z_{k-1}}^{z_{k}} \bar{Q}_{11}^{k}\left(1, z, \mathrm{z}^{2}\right) \mathrm{d} z \\
& A_{55}=k_{s} \sum_{k=1}^{N L} \int_{z_{k-1}}^{z_{k}} \bar{Q}_{55}^{k} \mathrm{~d} z
\end{aligned}
$$

where $N L$ denotes the number of composite layers. In the present wok, composite beams with simply supported boundary conditions and symmetric layups $\left(B_{i j}=0\right)$ are considered. It is also assumed that the structure is exposed to environments with uniform temperature distribution $(\Delta T=$ Constant $)$. Therefore, by combining equations (17), (19) and (20), the equilibrium equations can be obtained in terms of displacement components as follows:

$$
\begin{aligned}
& A_{11}\left(\frac{d^{2} u}{d x^{2}}+\frac{d w}{d x} \frac{d^{2} w}{d x^{2}}\right)=0 \\
& A_{55}\left(\frac{d \varphi}{d x}+\frac{d^{2} w}{d x^{2}}\right)+\frac{d w}{d x}\left(N_{x} \frac{d w}{d x}\right)=0 \\
& D_{11} \frac{d^{2} \varphi}{d x^{2}}-A_{55}\left(\varphi+\frac{d w}{d x}\right)=0
\end{aligned}
$$

\subsection{Pre-buckling deformation}

Since only perfectly flat pre-buckling configuration is considered in the present study, the pre-buckling deformation of the structure should be examined to assure that the beam remains flat under thermal environment. Khdeir (2001) showed that the deformation of the composite beam prior to buckling can be obtained by solving the equilibrium equations in which the non-linear terms are set to zero. Thus, the equilibrium position in the pre-buckling state follows the following equations: 


$$
\begin{aligned}
& A_{11} \frac{d^{2} u}{d x^{2}}=0 \\
& A_{55}\left(\frac{d \varphi}{d x}+\frac{d^{2} w}{d x^{2}}\right)=0 \\
& D_{11} \frac{d^{2} \varphi}{d x^{2}}-A_{55}\left(\varphi+\frac{d w}{d x}\right)=0
\end{aligned}
$$

Solving the ordinary differential Equations of (22) may lead to the following solution.

$$
\begin{aligned}
& u=c_{1} x+c_{2} \\
& w=-\frac{A_{55}}{D_{11}} c_{3} \frac{x^{3}}{6}+c_{4} \frac{x^{2}}{2}+c_{5} x+c_{6} \\
& \varphi=\frac{A_{55}}{D_{11}} c_{3} \frac{x^{2}}{2}-c_{4} x-c_{5}+c_{3}
\end{aligned}
$$

where $c_{1}$ to $c_{6}$ are constant which have to be determined using the associated boundary conditions. For simply supported boundary conditions we have:

$$
\begin{aligned}
& u=0 \text { at } \quad x=0, L \\
& w=0 \text { at } x=0, L \\
& M_{x}=0 \text { at } x=0, L
\end{aligned}
$$

It is seen that in order for Eq. (23) to satisfy the boundary conditions of Eq. (24), all constant $c_{1}$ to $c_{6}$ must be zero. Hence, it can be concluded that the considered composite beam follows bifurcation-type buckling. Furthermore, one can conclude that in the pre-buckling region, when the beam is completely undeformed, the generated force through the beam is equal to:

$$
\left.N_{x}\right|_{\text {pre-buckling }}=-N_{x}^{T}+N_{x}^{r}
$$

\subsection{Thermal buckling equations}

Here, in order to derive the thermal buckling equations, the adjacent-equilibrium criterion is implemented. According to this method, if $u_{0}, v_{0}$ and $\varphi_{0}$ are the displacement components of the equilibrium state of the composite beam, the displacement field related to a stable state adjacent to the initial equilibrium differs by $u_{1}, v_{1}$ and $\varphi_{1}$, which is very small but non-zero. Therefore, the total displacement components of the neighboring state can be written as: 


$$
\begin{aligned}
& u=u_{0}+u_{1} \\
& w=w_{0}+w_{1} \\
& \varphi=\varphi_{0}+\varphi_{1}
\end{aligned}
$$

Similar to the displacement components, for the stress resultants we have:

$$
\begin{aligned}
& N_{x}=N_{x 0}+N_{x 1} \\
& M_{x}=M_{x 0}+M_{x 1} \\
& Q_{x z}=Q_{x z 0}+Q_{x z 1}
\end{aligned}
$$

Then, Eqs. (26) and (27) are substituted into Eq. (21). It is seen that the terms with subscript 0 satisfy the equilibrium equations and can be removed from the equations. Moreover, considering that the non-linear terms with subscript 1 are very small compared to the linear terms, they are omitted from the equations (Brush and Almorth 1975; Kiani, Taheri, and Eslami 2011 ; Mirzavand and Eslami 2007). Therefore, the remaining terms form the following equations.

$$
\begin{aligned}
& \frac{d N_{x 1}}{d x}=0 \\
& \frac{d Q_{x z 1}}{d x}+N_{x 0} \frac{d^{2} w_{1}}{d x^{2}}=0 \\
& \frac{d M_{x 1}}{\partial x}-Q_{x z 1}=0
\end{aligned}
$$

which $N_{x 0}$ represents the thermal force induced in pre-buckling region, the value of which is calculated according to Eq. (25). Similarly, $N_{x 1}, M_{x 1}$ and $Q_{x z 1}$ can be obtained by inserting Eq. (27) into Eq. (19) and eliminating the non-linear terms with subscript 1 :

$$
\begin{aligned}
& N_{x 1}=A_{11} \frac{d u_{1}}{d x} \\
& M_{x 1}=D_{11} \frac{d \varphi_{1}}{d x} \\
& Q_{x z 1}=A_{55}\left(\varphi_{1}+\frac{d w_{1}}{d x}\right)
\end{aligned}
$$

Finally, Eq. (29) is substituted to Eq. (28). It is seen that the in-plane equation and the out of plane equations are decoupled. Therefore, the stability equations for the composite beam can be obtained as follows:

$$
\begin{aligned}
& A_{55}\left(\frac{d \varphi_{1}}{d x}+\frac{d^{2} w_{1}}{d x^{2}}\right)+\left(N_{x}^{r}-N_{x}^{T}\right) \frac{d^{2} w_{1}}{d x^{2}}=0 \\
& D_{11} \frac{d^{2} \varphi_{1}}{d x^{2}}-A_{55}\left(\varphi_{1}+\frac{d w_{1}}{d x}\right)=0
\end{aligned}
$$




\subsection{Analytical solution}

This subsection attempts to explain how to solve thermal buckling equations mentioned in Eq. (30). For composite beams with simply supported boundary conditions, an analytical solution is suggested in the form of:

$$
\begin{aligned}
& w_{1}(x)=W \sin \frac{n \pi}{L} x \\
& \varphi_{1}(x)=\Psi \cos \frac{n \pi}{L} x
\end{aligned}
$$

where $n$ denotes the number of half-wave in $x$-direction. It can be shown that the critical buckling temperature for the considered beam occurs when $n=1$. Thus, inserting Eq. (31) into Eq. (30) results in:

$$
\left[\begin{array}{cc}
\left(N_{x}^{r}-N_{x}^{T}+A_{55}\right)\left(\frac{\pi}{L}\right)^{2} & A_{55}\left(\frac{\pi}{L}\right) \\
A_{55}\left(\frac{\pi}{L}\right) & A_{55}+D_{11}\left(\frac{\pi}{L}\right)^{2}
\end{array}\right]\left[\begin{array}{l}
W \\
\Psi
\end{array}\right]=\left[\begin{array}{l}
0 \\
0
\end{array}\right]
$$

A nontrivial solution is sought for the above equation as follow:

$$
\operatorname{det}\left[\begin{array}{cc}
\left(N_{x}^{r}-N_{x}^{T}+A_{55}\right)\left(\frac{\pi}{L}\right)^{2} & A_{55}\left(\frac{\pi}{L}\right) \\
A_{55}\left(\frac{\pi}{L}\right) & A_{55}+D_{11}\left(\frac{\pi}{L}\right)^{2}
\end{array}\right]=0
$$

Solving Eq. (33) yields the following closed-form solution:

$$
N_{x}^{r}-\Delta T_{c r} \bar{N}_{x}^{T}=\frac{-D_{11}}{1+\left(\frac{D_{11}}{A_{55}}\right)\left(\frac{\pi}{L}\right)^{2}}\left(\frac{\pi}{L}\right)^{2}
$$

where

$$
\bar{N}_{x}^{T}=\sum_{k=1}^{N L} \int_{z_{k-1}}^{z_{k}} \bar{Q}_{11}^{k} \alpha_{x}^{k} \Delta T(1, z) \mathrm{d} z
$$

To find thermal buckling of composite beam, the value of $\Delta T$ increases gradually until Eq. (34) is satisfied with enough accuracy, as denoted by symbol $\Delta T_{c r}$. Then, $T_{c r}$ is calculated as follows:

$$
T_{c r}=\Delta T_{c r}+T_{0}
$$

Where $T_{0}$ is assumed to be $20^{\circ} \mathrm{C}$ in the present study as the room temperature. It is also clear that in the absence of SMA wires, the critical buckling temperature of the structure is obtained using the following relation. 


$$
T_{c r}=\frac{1}{\bar{N}_{x}^{T}} \frac{D_{11}}{1+\left(\frac{D_{11}}{A_{55}}\right)\left(\frac{\pi}{L}\right)^{2}}\left(\frac{\pi}{L}\right)^{2}+T_{0}
$$

\section{Results and discussion}

\subsection{Verification study}

Here, three examples are provided to verify the accuracy of the present results in predicting the buckling temperatures of composite beams with/without embedded SMA wires. First, in Table 8, the nondimensional critical buckling temperatures of a three-layer composite beam with lamination scheme of $\left[0^{\circ} / 90^{\circ} / 0^{\circ}\right]$ are obtained for different $h / L$ ratios and compared with the similar results reported by Emam and Eltaher (2016), Khdeir (2001), and Lee (1997). The material properties are assumed to be as follows:

$E_{1}=20 E_{2}, G_{12}=G_{13}=0.6 E_{2}, G_{23}=0.5 E_{2}, v_{12}=0.25, \alpha_{2} / \alpha_{1}=3$

As it is observed from Table 8, there is a very good agreement between the results of present work and the results of Emam and Eltaher (2016), Khdeir (2001), and Lee (1997) reporting based on first-order shear deformation theory, Reddy beam theory, and layerwise theory, respectively. As the second comparative example, the thermal buckling load of a $\left[0^{\circ} / 90^{\circ} / 0^{\circ}\right]$ composite beam is examined for different material properties and geometrical parameters. For this purpose, in Table 9, the non-dimensional buckling temperatures, $\bar{T}_{c r}=\Delta T_{c r}(L / h)^{2} / \alpha_{1}$, of the structure are calculated for various values of $E_{1} / E_{2}, \alpha_{1} / \alpha_{2}$ and $h / L$ parameters, and then compared with those obtained by Khdeir (2001). The material properties in this example are the same as those mentioned in the previous example. The comparison indicates that the differences between the present results and those obtained by Emam and Eltaher are negligible. Finally, as the third example, a verification study is performed to show that the Brinson model has been applied in the present research work accurately in order to predict the recovery stress generated by SMA wires. To this end, in Fig. 4, the variations of generated recovery stress versus temperature is depicted for different prestrain values. Then, the results are compared with the similar values obtained by Asadi et al. (2013a). It should be noted that the results of their study are plotted as figure, and thus digitizer software with high accuracy is used to determine the required numerical values. Fig. 4 elucidates that the results are so close to each other and there is no significant difference between them. Therefore, based on these three comparative examples, it is concluded that the presented results are accurate enough to handle the thermal buckling analysis composite beams with/without embedded SMA wires. 


\subsection{Thermal buckling of composite beams with embedded SMA wires}

In this section, the performance of SMA wires on the thermal buckling of composite beams is evaluated. The base composite beam consists of epoxy and graphite fibers with thermo-mechanical properties as listed in Table 3. The SMA material is also selected based on the research conducted by Asadi et al. (2013b) whose thermomechanical properties are presented in Table 4. It should be noted that in all examples of subsections 4.2- 4.4, a composite beam consists of eight layers of equal thickness with lamination scheme of $\left[0^{\circ} / 90^{\circ} / 0^{\circ} / 90^{\circ}\right]_{s}$ and the following assumptions are considered.

- The SMA wires are assumed to be aligned with the graphite fibers. Otherwise, the orientation mismatching may cause some non-fiber spaces which makes the resin brittle. This phenomenon reduces the lifetime, integrity and reliability of composite structures (Tsoi et al. 2003).

- The SMA wires are embedded in the outermost $0^{\circ}$-layers of the beam. This is because, if the wires are embedded in the $90^{\circ}$-layers, the recovery stresses generated by the SMA wires do not enhance the buckling of the structure, and even its stiffness and thus its critical buckling temperature may decrease. Furthermore, Asadi et al. (2013a) showed that for SMA-reinforced composite beams which include $0^{\circ}$ layers, the choice of $0^{\circ}$-layer as the location of SMA wires has no noticeable effect on the buckling.

- The material properties are independent of temperature. Asadi et al. (2013a) showed that the influence of material dependence on temperature on the buckling behavior of composite beams with embedded SMA wires can only be detected at temperatures above $300{ }^{\circ} \mathrm{C}$. Therefore, in the present work at which the focus is on the lower operating temperatures (below glass transition temperature), the assumption that the material properties are not dependent on temperature is reasonable and acceptable.

- Unless otherwise stated, the values of volume fraction and pre-strain for the SMA wires are considered to be $10 \%$ and $1 \%$, respectively. It is shown in the numerical examples of this subsection that these values are sufficient to enhance the buckling temperature as needed.

First, the effects of volume fraction and pre-strain of SMA wires on the critical buckling temperature of the composite beam are examined. The numerical results of Table 10 indicate that, except for states with no pre-strain SMAs, in other cases by increasing the volume fraction of reinforcing wires, the buckling temperature of the structure enhances. Here is a description of how SMA wires affect the buckling of the structure. As briefly mentioned in the Introduction section, when the composite beams are heated, the prestrained SMA wires are prevented from recovering their initial strains. This makes them produce a large amount of tensile recovery stress, as observed in Fig. 4. Since the recovery stress of SMAs is of the tensile type, it reduces the residual thermal stress in the structure. Therefore, the structure can be used at higher 
temperatures without encountering buckling. As a numerical example, consider a composite beam with $L / h=125$. In this case, the structure can withstand a maximum compressive load of about $\bar{N}_{x}=38.6 \mathrm{KN} / \mathrm{m}$ which is generated at a temperature of $T_{c r}=61.0^{\circ} \mathrm{C}$, and then suffers from the phenomenon of buckling (Fig. 5). Now, if 5\% SMA wires are added to the outer most layers, this amount of axial force that causes the structure to buckle generates at higher temperature around $T_{c r}=130.2^{\circ} \mathrm{C}$. Therefore, it is observed that SMAs can considerably delay the critical buckling temperature of the structure. Obviously, by increasing the volume fraction of SMAs, the generated tensile recovery force in the beams increases and so they are more capable of withstanding thermal compressive stresses, and as a result, the critical buckling temperature is delayed. When the SMAs are embedded in the structures without pre-strain, as the temperature rises, there is no tensile recovery stress in the structure and the effect of these wires is limited to their mechanical and physical properties such as Young's modulus and CTE. By comparing the properties of the base composite and the SMA wires, it is found that the Young's modulus of the wires is $67 \mathrm{GPa}$ in their maximum state in the austenite phase, which is less than its longitudinal modulus of graphite fiber/epoxy composites. For this reason, the addition of SMA wires without pre-strain may reduce the overall stiffness of the structure.

The effect of adding SMA wires on the critical buckling temperature of composite beams for different $h / L$ ratios is studied, and the results are reported in Fig. 6 and Table 11. The first point to note in this figure is that for the beam with $h / L$ ratio equal to or less than 0.005, using SMA wires not only does not increase the buckling temperature, but may reduce it. Initially, this result is inconsistent with what is expected from the addition of SMAs, but one can find the reason of the behavior. To justify this, for example, consider a beam with $h / L=0.005$ where the temperature of $36.0^{\circ} \mathrm{C}$ leads to its buckling. But, according to Table 4, it is observed that the austenite start and austenite finish temperatures of the SMA wires are $34.5^{\circ} \mathrm{C}$ and $49.0^{\circ} \mathrm{C}$, respectively. This means that before the martensite phase is completely converted to austenite and the recovery stress is produced, the buckling phenomenon occurs in the structure. Thus, not only the tensile force is not produced enough, but by adding shape memory wires to the structure, the overall stiffness of the structure may decrease and as observed from Fig. 6 and Table 11, the beam buckles at lower temperature $\left(35.4^{\circ} \mathrm{C}\right.$ ). For this reason, the addition of SMAs may play a destructive role in resisting thermal buckling before the austenite starting temperature (and even slightly above that). Therefore, depending on the austenitic starting temperature value, a minimum thickness-to-width ratio $\left(\left.\frac{h}{L}\right|_{\min }\right)$ can be defined for the use of SMA wires which for the values less than that, utilizing these reinforcing wires to 
raise the buckling temperature has no justification. By this definition, the $\left.\frac{h}{L}\right|_{\min }$ for graphite/epoxy composite beams is a value between 0.005 and 0.006. Fig. 6 also indicates that for beams with $\frac{h}{L}$ equal to or higher than $\left.\frac{h}{L}\right|_{\min }$, the use of SMA wires can play a very effective role in delaying thermal buckling. In particular, when the thickness ratio is 0.006 , SMA wires sharply changes the buckling temperature from $43.1^{\circ} \mathrm{C}$ to $180.8^{\circ} \mathrm{C}$ (320\% enhancement). Fig. 7 shows the improvement of $T_{c r}$ versus thickness due to the embedding shape memory wires. It is observed that by increasing the thickness of the structure from 0.003 to the $\left.\frac{h}{L}\right|_{\min }$, SMA wires do not play an effective role in the buckling temperature. At $\left.\frac{h}{L}\right|_{\min }$, the role of the shape memory alloys is very significant, and subsequently, with increasing the beam thickness, the positive effect of these wires is lessened.

Another point to note is comparing the buckling temperature of the structure with the physical properties of its constituents. As can be seen from Fig. 6 and Table 11, the buckling temperature can reach as high as $293.7^{\circ} \mathrm{C}$ for the beam with $\frac{h}{L}$ ratio of 0.015 and $10 \%$ SMA in the outermost layers, but the crucial matter is that the cost to reach this temperature is not reasonable because the structure reaches the polymer glass transition temperature before experiencing the critical buckling temperature, which destroys the overall of the structure. Therefore, $\boldsymbol{T}_{g}$ must also be included in the calculations before embedding shape memories into the structure. As mentioned before, the $T_{g}$ of the polymer used in the present study is about $112.5^{\circ} \mathrm{C}$. With this explanation and considering the results in Fig. 6 and Table 11, it can be concluded that for composite beams with the given lamination scheme, the use of SMAs for a thickness-to-length ratio equal or greater than 0.012 has no justification. In other words, the maximum real and practical $\frac{h}{L}$ ratio for the beam to be reinforced by SMA wires is defined by $\left.\frac{h}{L}\right|_{\max }$ which its value is 0.012 for the graphite/epoxy composite beams. Furthermore, as it is observed from Table 11, using only 10\% SMA is enough to improve the critical buckling temperature because this amount of shape memory wires can raise the buckling temperature above the permitted temperature $\left(\boldsymbol{T}_{g}\right)$ for all required thickness $\left(\left.\frac{h}{L}\right|_{\min }<\frac{h}{L}<\left.\frac{h}{L}\right|_{\max }\right)$. 


\subsection{Thermal buckling of composite beams reinforced by CNTs}

As discussed in the previous subsection, the use of SMA wires in composite beams has its limitations for applications in some temperature ranges or thicknesses. They also make the structure heavier which can seriously affect its vibrational behavior. Thus, it would be better to reduce the volume fraction of SMAs as much as possible or even look for a better alternative material. Therefore, in this subsection, the effect of CNTs on the thermal buckling of the composite beams is studied. Unlike SMA wires that different parameters such as volume fraction, pre-strain and angle of the wires can significantly affect their performance, there is no specific design parameter for CNTs because, as described before in subsection 2.3, the nanotubes are dispersed uniformly in the matrix phase at $0.3 \mathrm{wt} \%$ loading. It should be mentioned that the material properties considered here are based on the data in Table 7. Before addressing the results, it is important to note that, as can be observed from Table 7, by adding CNTs into the structure the longitudinal CTE of composite becomes negative which is compatible with the CTE of graphite fibers (Cohades and Michaud 2018).

Now, the effect of CNTs on the buckling temperature of the structure is investigated for different thickness to length ratios and the results are presented in Table 11 and Fig. 8. The most important point which can be concluded from the results is that in contrast to the SMA wires that play a positive role in the thermal buckling of the beam only at a specific thickness range $\left(\frac{h}{L} \geq 0.006\right)$, the nanotubes increase the critical buckling temperature of the structure at all thicknesses. It means for composite beams with $\frac{h}{L} \leq 0.005$, it is more reasonable to use CNTs as reinforcement materials. On the other hands, due to the limitation of $T_{g}$ which discussed earlier, the buckling phenomenon can occur only when $\frac{h}{L} \leq 0.012$. By focusing on the analytical results tabulated in Table 11, it is concluded that when $\frac{h}{L}$ ranges between 0.010 and 0.012, it is recommended to use CNTs in the structure instead of SMA wires because, at this thickness range, CNTs are able to increase the buckling temperature of the structure to near or above $T_{g}$ and there is no need to raise the buckling temperature further. Thus, only for $0.006 \leq \frac{h}{L} \leq 0.009$, SMAs can perform better than the nanotubes at raising the buckling temperature of the structure. The effect of CNTs on the enhancement of the buckling temperature of composite beams against $\frac{h}{L}$ ratio is also depicted in Fig. 9. From Table 11 and Figs. 8-9, one can also conclude that though CNTs have always positive influence on 
the thermal buckling of composite beams, the increase in buckling temperature that CNTs can cause in very thin composite beams is negligible, but significant for thicker structures.

\subsection{Thermal buckling of hybrid SMA/CNT composite beam}

In the two subsections 4.2 and 4.3, the influences of using SMA wires and CNTs on thermal buckling of composite beams were examined. As discussed, both materials have some advantages and disadvantages. The shape memory wires have a strong ability to improve buckling temperatures, but they are active only at a specific range of temperature. They also can be destructive in the buckling if they are implemented for very thin composite beams. Furthermore, they make the structure heavier and provide the conditions for structural failure due to the difference between the long fibers and shape memory wires materials. On the other hands, the CNTs enhance the thermal buckling behavior of the composite beam at all temperatures and thicknesses, but they have a limited potential to increase the critical buckling temperature of the structure, especially at low ranges of $\frac{h}{L}$ ratio. Thus, the problem is that at some conditions, like very thin beams, the critical buckling temperature is required to be increased to a desired level. In these cases, neither SMAs nor CNTs can fulfill the desired purpose. Therefore, a new solution should be found for this problem. Here, the idea of combining both SMAs and CNTs is investigated. The main goal is to use the advantages of both SMA wires and CNTs and reduce the volume fraction of SMAs in the structure as much as possible.

In Table 11, the effect of using only SMA wires, only CNTs and simultaneous use of them on the buckling temperature of the composite beam is examined. It is observed that for $\frac{h}{L}<0.005$, CNTs have a better influence on the thermal buckling, but for thicker beams, SMAs perform better than CNTs. However, it is seen that using both materials simultaneously always improve the buckling behavior of the structure. An interesting result can be observed by focusing on the case with thickness to length ratio of 0.005 . In this case, it can be found that SMAs do not have any positive impact on the buckling temperature of the beam and the CNTs raise it by only $6.9^{\circ} \mathrm{C}$. However, by simultaneous use of these materials, the critical buckling temperature changes from 36.0 to $235.1^{\circ} \mathrm{C}$ which means $550 \%$ increase in $T_{c r}$. To justify this, it should be mentioned that the SMAs can affect the buckling temperatures provided that the wires are activated. The numerical results show that the buckling temperature of the base composite beam is $36.0^{\circ} \mathrm{C}$ which is not enough higher than SMA activation temperature, and therefore, no tensile recovery stresses can be generated. At this condition, adding $0.3 \mathrm{wt} \%$ CNTs inti the polymer matrix can increase the buckling 
temperature only for a small amount, but sufficiently above austenite start temperature where the SMA wires become active to significantly enhance the stiffness, and consequently, the critical buckling temperature of the structure.

As mentioned earlier, it is usually better to decrease the amount of SMA wires in the structure as much

as possible. Consider a graphite/epoxy composite beam with $\frac{h}{L}=0.006$ which its critical buckling is about $43.1^{\circ} \mathrm{C}$. Here, the goal is to enhance the buckling temperature of the structure to its highest possible level, which is equal to $T_{g}$, i.e. $112.5^{\circ} \mathrm{C}$. To this end, in Fig. 10, a graph is drawn which shows the variations of buckling temperature of the beam against SMA volume fraction. It is seen that the $V s$ must be 5\% to delay the buckling temperature above glass transition temperature $\left(T_{c r}=112.8^{\circ} \mathrm{C}\right)$. Then, in another graph, the variations of buckling temperature against $V s$ is depicted when the matrix phase includes CNTs. For this case, one can see that only 3\% SMA wires can increase the critical buckling temperature to $112.6^{\circ} \mathrm{C}$. Therefore, it is found that, the use of CNTs may lead to a decrease in the required amount of SMAs.

\section{Conclusion}

In the present work, thermal buckling of a laminated composite beam reinforced by advanced materials was examined. The composite beam was assumed to be exposed a thermal environment with uniform temperature distribution. To reduce the damaging effects of thermal stresses, SMA wires and CNTs were applied as reinforcing materials in the structure. Despite the many published research works on SMA or CNT-reinforced composite beams, here, the focus was on the actual operating conditions of these materials. To this end, first, some experimental tests for thermal properties of the composite beam were conducted. Then, the governing equations were derived based on TBT and solved analytically for simply supported boundary conditions. A comprehensive study was performed to investigate the role of SMA wires and CNTs in thermal buckling of the composite beam. It was concluded that using shape memory wires or nanotubes can have both advantages and disadvantages, and each of them is suitable only for specific conditions. In other words, depending on the thickness of structure or operating temperature, one reinforcing material can outperform the other one. Finally, it was found that for some conditions neither SMAs nor CNTs can have a considerable influence on buckling characteristics of the structure, but with simultaneous use of these two materialss, the critical buckling temperature can be extraordinarily improved. 


\section{Acknowledgement}

The study was supported by the National Research Foundation of Korea (NRF) grant funded by the Korea government (2018R1A6A1A03024509, 2019R1A2B5B03004980).

\section{References}

Abdollahi, H., S. E. Esfahani, M. Shakeri and M. R. Eslami. 2015. Non-linear thermal stability analysis of SMA wire-embedded hybrid laminated composite Timoshenko beams on non-linear hardening elastic foundation. Journal of Thermal Stresses 38(3): 277-308. doi: 10.1080/01495739.2014.985569.

Abid, F., A.E. Hami, T. Merzouki, L. Walha and M. Haddar. 2019. An approach for the reliability-based design optimization of shape memory alloy structure. Mechanics Based Design of Structures and Machines. Published online. doi: 10.1080/15397734.2019.1665541.

Allaoui, A. and N. El Bounia. 2009. How carbon nanotubes affect the cure kinetics and glass transition temperature of their epoxy composites-A review. Express Polymer Letters, BME-PT Hungary 3 (9): 588594. doi: 10.3144/expresspolymlett.2009.73 .

Asadi, H., M. Bodaghi, M. Shakeri and M.M. Aghdam. 2013a. On the free vibration of thermally pre/postbuckled shear deformable SMA hybrid composite beams. Aerospace Science and Technology. 31(1): 73-86. doi: 10.1016/j.ast.2013.09.008.

Asadi, H., M. Bodaghi, M. Shakeri and M. M. Aghdam. 2013b. An analytical approach for nonlinear vibration and thermal stability of shape memory alloy hybrid laminated composite beams. European Journal of Mechanics-A/Solids 42: 454-468. doi: 10.1016/j.euromechsol.2013.07.011.

Asadi, H., M. Eynbeygi and Q. Wang. 2014a. Nonlinear thermal stability of geometrically imperfect shape memory alloy hybrid laminated composite plates. Smart materials and structures, 23(7): 075012. doi: 10.1088/0964-1726/23/7/075012.

Asadi, H., Y. Kiani, M. Shakeri and M. R. Eslami. 2014b. Exact solution for nonlinear thermal stability of geometrically imperfect hybrid laminated composite Timoshenko beams embedded with SMA fibers. Journal of Engineering Mechanics 141(4): 04014144.

Barai, P. and G. J. Weng. 2011. A theory of plasticity for carbon nanotube reinforced composites. International Journal of Plasticity 27(4): 539-559. doi: 10.1016/j.ijplas.2010.08.006.

Bayat, Y. and H. EkhteraeiToussi. 2017. Exact solution of thermal buckling and post buckling of composite and SMA hybrid composite beam by layerwise theory. Aerospace Science and Technology 67: 484-494. doi: 10.1016/j.ast.2017.04.029.

Bouazza, M., N. Benseddiq and A. M. Zenkour. 2019. Thermal buckling analysis of laminated composite beams using hyperbolic refined shear deformation theory. Journal of Thermal Stresses 42 (3): 332-340. doi: 10.1080/01495739.2018.1461042.

Brinson, L. C. 1993. One-dimensional constitutive behavior of shape memory alloys: thermomechanical derivation with non-constant material functions and redefined martensite internal variable. Journal of intelligent material systems and structures 4(2): 229-242. doi: 10.1177/1045389X9300400213.

Brinson, L. C. and M. S. Huang. 1993. Simplifications and comparisons of shape memory alloy constitutive models. Journal of intelligent material systems and structures 7 (1): 108-114. doi: 10.1177/1045389X9600700112.

Brush D. O. and B. O. Almorth, Buckling of Bars, Plates, and Shells, McGraw-Hill, New York, 1975. 
Cohades, A. and V. Michaud. 2018. Shape memory alloys in fibre-reinforced polymer composites. Advanced Industrial and Engineering Polymer Research 1 (1): 66-81. doi: 10.1016/j.aiepr.2018.07.001.

Ebrahimi, F. and N. Farazmandnia. 2018. Thermal buckling analysis of functionally graded carbon nanotubereinforced composite sandwich beams. Steel and composite structures 27(2): 149-159. doi: 10.12989/scs.2018.27.2.149.

Emam, Samir, and M. A. Eltaher. 2016. Buckling and postbuckling of composite beams in hygrothermal environments. Composite Structures 152: 665-675. doi: 10.1016/j.compstruct.2016.05.029.

Guida, M., A. Sellitto, F. Marulo and A. Riccio. 2019. Analysis of the impact dynamics of shape memory alloy hybrid composites for advanced applications. Materials 12(1):153. doi: 10.3390/ma12010153.

He, Y., S. Yang, H. Liu, Q. Shao, Q. Chen, C. Lu, Y. Jiang, C. Liu and Z. Guo. 2018. Reinforced carbon fiber laminates with oriented carbon nanotube epoxy nanocomposites: magnetic field assisted alignment and cryogenic temperature mechanical properties. Journal of colloid and interface science 517: 40-51. doi: 10.1016/j.jcis.2018.01.087.

Jermsittiparsert, K., A. Ghabussi, A. Forooghi, A. Shavalipour, M. Habibin, D. Jung and M. Safa. 2020. Critical voltage, thermal buckling and frequency characteristics of a thermally affected GPL reinforced composite microdisk covered with piezoelectric actuator. Mechanics Based Design of Structures and Machines, Published online, doi: 10.1080/15397734.2020.1748052.

Jhou, W.T., C. Wang, S. Ii, H.S. Chiang and C.H. Hsueh. 2018. TiNiCuAg shape memory alloy films for biomedical applications. Journal of Alloys and Compounds 738: 336-344. doi: 10.1016/j.jallcom.2017.12.194.

Jin, T., N. S. Ha, V. T. Le, N. S. Goo and H. C. Jeon. 2015. Thermal buckling measurement of a laminated composite plate under a uniform temperature distribution using the digital image correlation method. Composite Structures 123: 420-429. doi: 10.1016/j.compstruct.2014.12.025.

Kamarian, S., M. Bodaghi, R. Barbaz Isfahani, M. Shakeri and M. H. Yas. 2019. "Influence of carbon nanotubes on thermal expansion coefficient and thermal buckling of polymer composite plates: experimental and numerical investigations. Mechanics Based Design of Structures and Machines. Published Online. doi: 10.1080/15397734.2019.1674664.

Kamarian, S. and M. Shakeri. 2017. Thermal buckling analysis and stacking sequence optimization of rectangular and skew shape memory alloy hybrid composite plates. Composites Part B: Engineering: 116: 137-152. doi: 10.1016/j.compositesb.2017.01.059.

Khdeir, A. A. 2001. Thermal buckling of cross-ply laminated composite beams. Acta mechanica 149 (1-4): 201213. doi: 10.1007/BF01261672.

Kiani, Y., S. Taheri, and M. R. Eslami. 2011. Thermal buckling of piezoelectric functionally graded material beams. Journal of Thermal Stresses 34(8): 835-850. doi: 10.1080/01495739.2011.586272.

Lee, J. 1997. Thermally induced buckling of laminated composites by a layerwise theory. Computers \& structures 65(6): 917-922. doi: 10.1016/S0045-7949(96)00232-5.

Liu, L., G. A. Kardomateas, V. Birman, J. W. Holmes and G. J. Simitses. 2006. Thermal buckling of a heatexposed, axially restrained composite column. Composites Part A: Applied Science and Manufacturing 37 (7): 972-980. doi:10.1016/j.compositesa.2005.04.006.

Maghsoudlou, M.A., R. B. Isfahani, S. Saber-Samandari and M. Sadighi. 2019. Effect of interphase, curvature and agglomeration of SWCNTs on mechanical properties of polymer-based nanocomposites: Experimental and numerical investigations. Composites Part B: Engineering 175:107119. doi:10.1016/j.compositesb.2019.107119.

Miglani, J., B. Devarajan and R.K. Kapania. 2018. Thermal buckling analysis of periodically supported composite beams using Isogeometric analysis. AIAA/ASCE/AHS/ASC Structures, Structural Dynamics, and Materials Conference : 1224. doi: 10.2514/6.2018-122 .

Mirzavand, B., and M. R. Eslami. 2007. Thermal buckling of simply supported piezoelectric FGM cylindrical shells. Journal of Thermal Stresses 30(11): 1117-1135. doi: 10.1080/01495730701416036. 
Nasakina, E.O., M.A. Sevost'yanov, A.B. Mikhailova, M.A. Gol'dberg, K.Y. Demin, A.G. Kolmakov and V.T. Zabolotnyi. 2015. Preparation of a nanostructured shape-memory composite material for biomedical applications. Inorganic Materials 51(4): 400-404. doi: 10.1134/S0020168515040093.

Panda, S. K. and B. N. Singh. 2013. Thermal postbuckling behavior of laminated composite spherical shell panel using NFEM\#. Mechanics Based Design of Structures and Machines 41 (4): 468-488. doi: 10.1080/15397734.2020.1748052.

Qian, D., E.C. Dickey, R. Andrews and T. Rantell. 2000. Load transfer and deformation mechanisms in carbon nanotube-polystyrene composites. Applied physics letters 76(20): 2868-2870. doi: 10.1063/1.126500@apl.2019.APLCLASS2019.issue-1.

Rahman, M.M., M. Hosur, A.G. Ludwick, S. Zainuddin, A. Kumar, J. Trovillion and S. Jeelani. 2012a. Thermomechanical behavior of epoxy composites modified with reactive polyol diluent and randomly-oriented amino-functionalized multi-walled carbon nanotubes. Polymer Testing 31(6): 777-784. doi: 10.1016/j.polymertesting.2012.05.006.

Rahman, M.M., S. Zainuddin, M. V. Hosur, J. E. Malone, M.B.A. Salam, A. Kumar and S. Jeelani. 2012 b. Improvements in mechanical and thermo-mechanical properties of e-glass/epoxy composites using amino functionalized MWCNTs. Composite Structures. 94(8): 2397-2406. doi: 10.1016/j.compstruct.2012.03.014.

Reddy, J.N., 2003. Mechanics of laminated composite plates and shells: theory and analysis. CRC press.

Salim, M., M. Bodaghi, S. Kamarian and M. Shakeri. 2018. Free vibration analysis and design optimization of SMA/Graphite/Epoxy composite shells in thermal environments. Latin American Journal of Solids and Structures 15 (1). doi: 10.1590/1679-78253070.

Shi, X., S. Li, F. Chang and D. Bian. 2014. Postbuckling and failure analysis of stiffened composite panels subjected to hydro/thermal/mechanical coupled environment under axial compression. Composite Structures 118: 600-606. doi: 10.1016/j.compstruct.2014.08.022.

Shiau, L.C. and S.Y. Kuo. 2004. Thermal buckling of composite sandwich plates. Mechanics based design of structures and machines 32(1): 57-72. doi: 10.1081/SME-120026590.

Siddiqui, N.A., M.L. Sham, B.Z. Tang, A. Munir and J.K. Kim, 2009. Tensile strength of glass fibres with carbon nanotube-epoxy nanocomposite coating. Composites Part A: Applied Science and Manufacturing 40(10): 1606-1614. doi: 10.1016/j.compositesa.2009.07.005.

Song, M., L. Chen, J. Yang, W. Zhu and S. Kitipornchai. 2019. Thermal buckling and postbuckling of edgecracked functionally graded multilayer graphene nanocomposite beams on an elastic foundation. International Journal of Mechanical Sciences: 161-162: 105040. doi: 10.1016/j.ijmecsci.2019.105040.

Spanos, P.D. and A. Kontsos. 2008. A multiscale Monte Carlo finite element method for determining mechanical properties of polymer nanocomposites. Probabilistic Engineering Mechanics 23(4): 456-470. doi: 10.1016/j.probengmech.2007.09.002.

Tsoi, K. A., R. Stalmans, J. Schrooten, M. Wevers and Y. W. Mai. 2003. Impact damage behaviour of shape memory alloy composites. Materials Science and Engineering A 342 (1-2): 207-215. doi: 10.1016/S09215093(02)00317-9.

Van, D., V. Nguyen and C. Lee. 2019. Quasi-3D isogeometric buckling analysis method for advanced composite plates in thermal environments. Aerospace Science and Technology 92: 34-54. doi: 10.1016/j.ast.2019.05.056.

$\mathrm{Wu}, \mathrm{H}$., S. Kitipornchai and J. Yang. 2017. Imperfection sensitivity of thermal post-buckling behaviour of functionally graded carbon nanotube-reinforced composite beams. Applied Mathematical Modelling 42: 735-752. doi: 10.1016/j.apm.2016.10.045.

Zhang, J., S. Pan and L. Chen. 2019. Dynamic thermal buckling and postbuckling of clamped-clamped imperfect functionally graded annular plates. Nonlinear Dynamics 95(1): 565-577. doi: 10.1007/s11071-018-4583-5.

Zhu, J., H. Peng, F. Rodriguez-Macias, J. L. Margrave, V. N. Khabashesku, A. M. Imam, K. Lozano and E. V. Barrera. 2004. Reinforcing epoxy polymer composites through covalent integration of functionalized nanotubes. Advanced Functional Materials 14 (7): 643-648. doi: 10.1002/adfm.200305162. 


\section{Appendix 1}

$$
\begin{aligned}
& E_{11}=E_{f} V_{f}+E_{m}\left(1-V_{f}\right) \quad ; \quad E_{22}=E_{m}\left[\left(1-\sqrt{V_{f}}\right)+\frac{\sqrt{V_{f}}}{1-\sqrt{V_{f}}\left(1-\frac{E_{m}}{E_{2 f}}\right)}\right] \\
& G_{12}=G_{13}=G_{m}\left[\left(1-\sqrt{V_{f}}\right)+\frac{\sqrt{V_{f}}}{1-\sqrt{V_{f}}\left(1-\frac{G_{m}}{G_{12 f}}\right)}\right] \\
& \alpha_{1}=\frac{V_{f} \alpha_{f} E_{f}+\left(1-V_{f}\right) \alpha_{m} E_{m}}{E_{11}} \quad ; \quad \alpha_{2}=\frac{E_{m}}{E_{22}}\left[\alpha_{m}\left(1-\sqrt{V_{f}}\right)+\frac{\alpha_{m} \sqrt{V_{f}}-V_{f}\left(\alpha_{m}-\alpha_{2 f}\right)}{1-\sqrt{V_{f}}\left(1-\frac{E_{m}}{E_{f}}\right)}\right] \\
& v_{12}=v_{12 f} V_{f}+v_{12 m}\left(1-V_{f}\right) ; \rho=\rho_{f} V_{f}+\rho_{m}\left(1-V_{f}\right)
\end{aligned}
$$

where the subscripts ' $m$ ' and ' $f$ ' mean the matrix and fiber, respectively. Also, parameters

$E, G, v, \alpha, \rho$ and $V_{f}$ denote Young modulus, shear modulus, Poisson ratio, thermal expansion coefficient, material density and volume fraction of fibers, respectively 


\section{Appendix 2}

$\bar{Q}_{11}=Q_{11} \cos ^{4} \theta+2\left(Q_{12}+2 Q_{66}\right) \operatorname{Sin}^{2} \theta \operatorname{Cos}^{2} \theta+Q_{22} \operatorname{Sin}^{4} \theta$

$\bar{Q}_{55}=Q_{44} \operatorname{Sin}^{2} \theta+Q_{55} \operatorname{Cos}^{2} \theta$

where $\theta$ is the angle that the fibers of $k^{\text {th }}$ lamina makes with the structure $x$-axis, and $Q_{i j}$, called the plane stress-reduced stiffnesses, are given by (Reddy 2003):

$Q_{11}=\frac{E_{1}}{1-v_{12} v_{21}}$

$Q_{12}=\frac{v_{12} E_{2}}{1-v_{12} v_{21}}=\frac{v_{21} E_{1}}{1-v_{12} v_{21}}$

$Q_{22}=\frac{E_{2}}{1-v_{12} v_{21}}$

$Q_{44}=G_{23}$

$Q_{55}=G_{13}$

$Q_{66}=G_{12}$

Where, $E_{1}, E_{2}, G_{12}$ and $v_{12}$ are the independent material constants. 


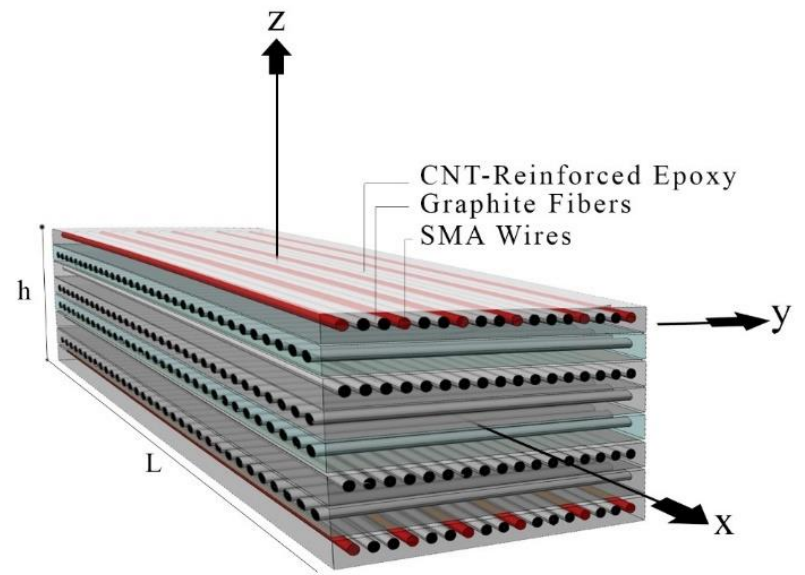

Fig 1 Schematic of a hybrid SMA/CNT laminated composite beam

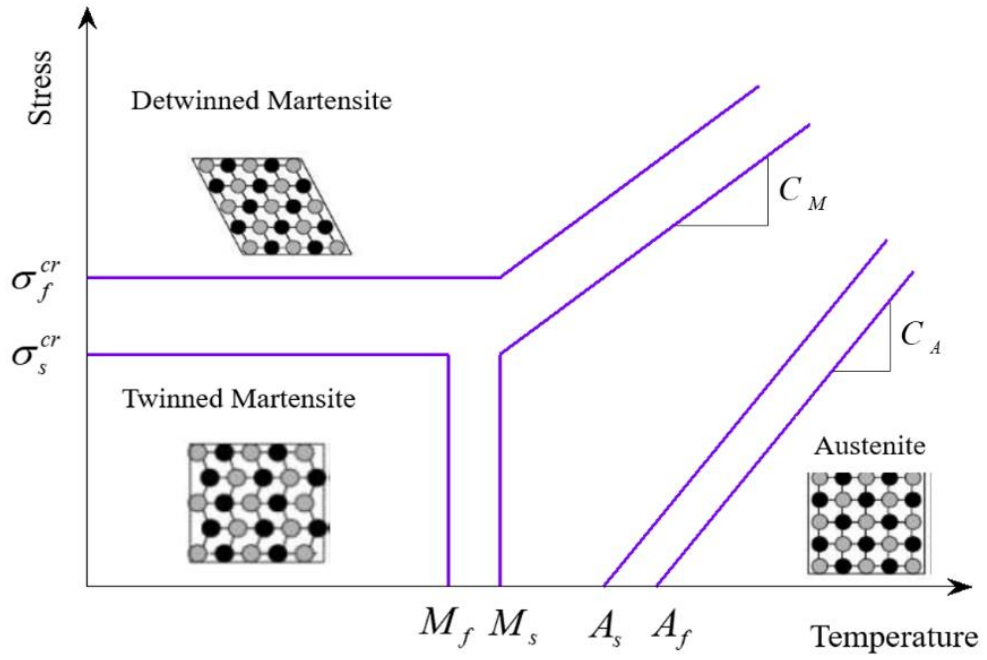

Fig 2 Schematic phase diagram for SMAs 
Step 1

Adding 0.3 wt. $\% \mathrm{CNT}$
to the epoxy resin

Step 7

Conducting DMTA \&
TMA tests

Step 2

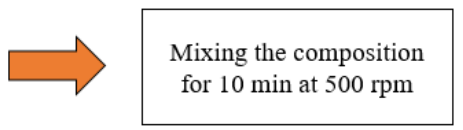

for 10 min at $500 \mathrm{rpm}$

Step 6

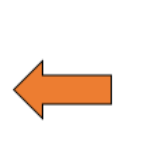

Step 3

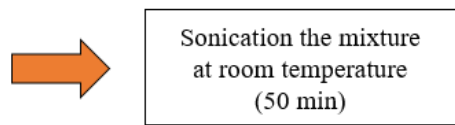

$(50 \mathrm{~min})$

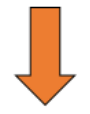

Step 4

Adding hardener to the mixture

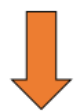

Step 5

Degassing process (15 min)

Fig 3 Preparation of CNT/epoxy samples 


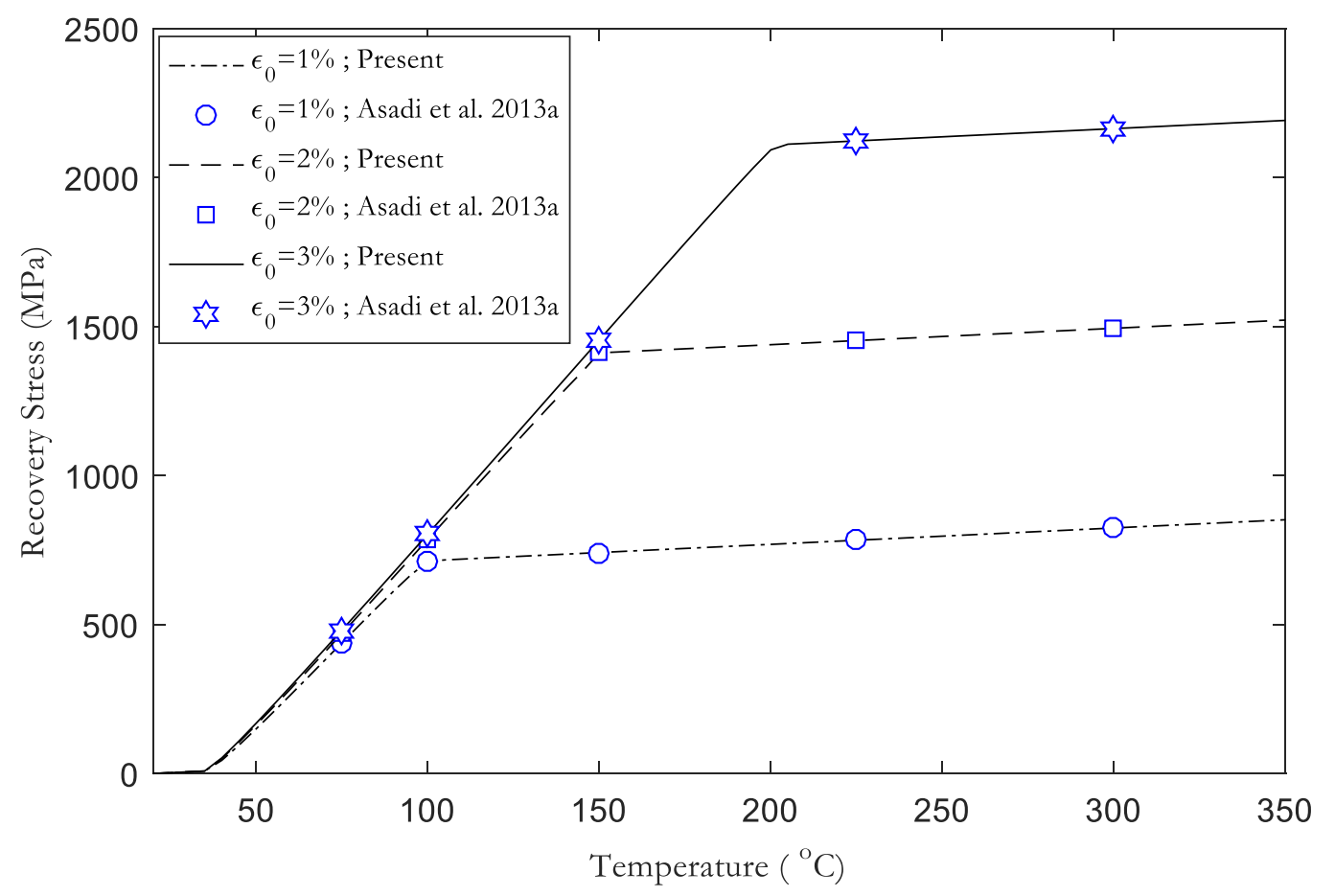

Fig 4 SMA recovery stress versus temperature with different pre-strains

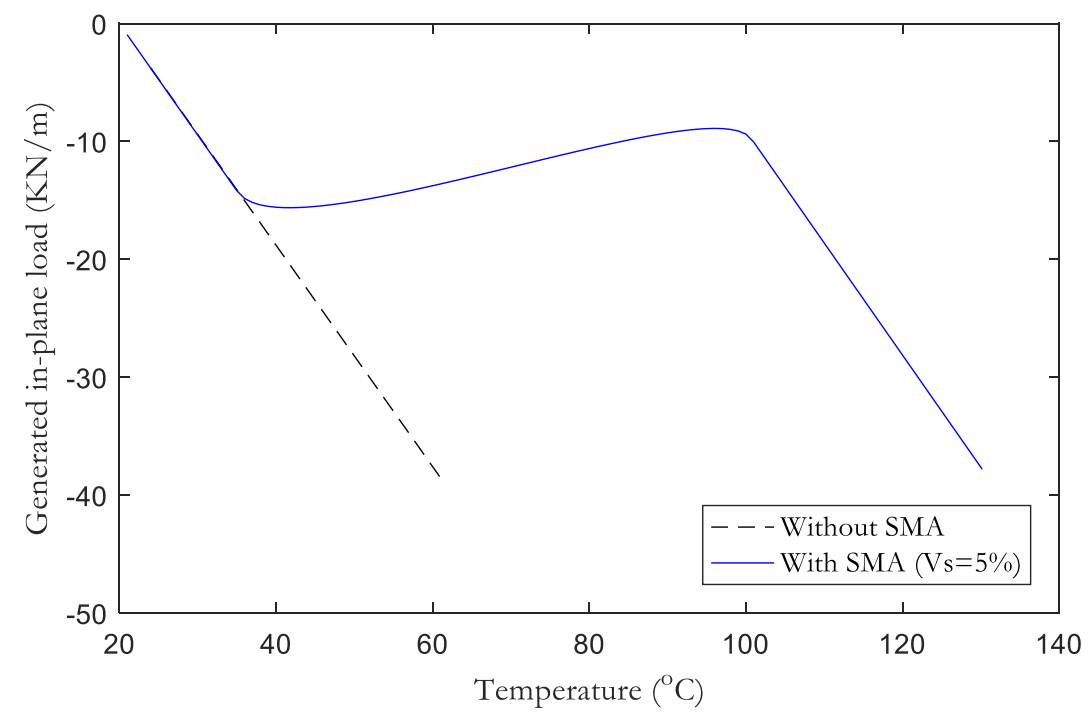


Fig 5 Effect of SMA wires on the axial compressive force generated in the graphite/epoxy composite beam at different temperatures

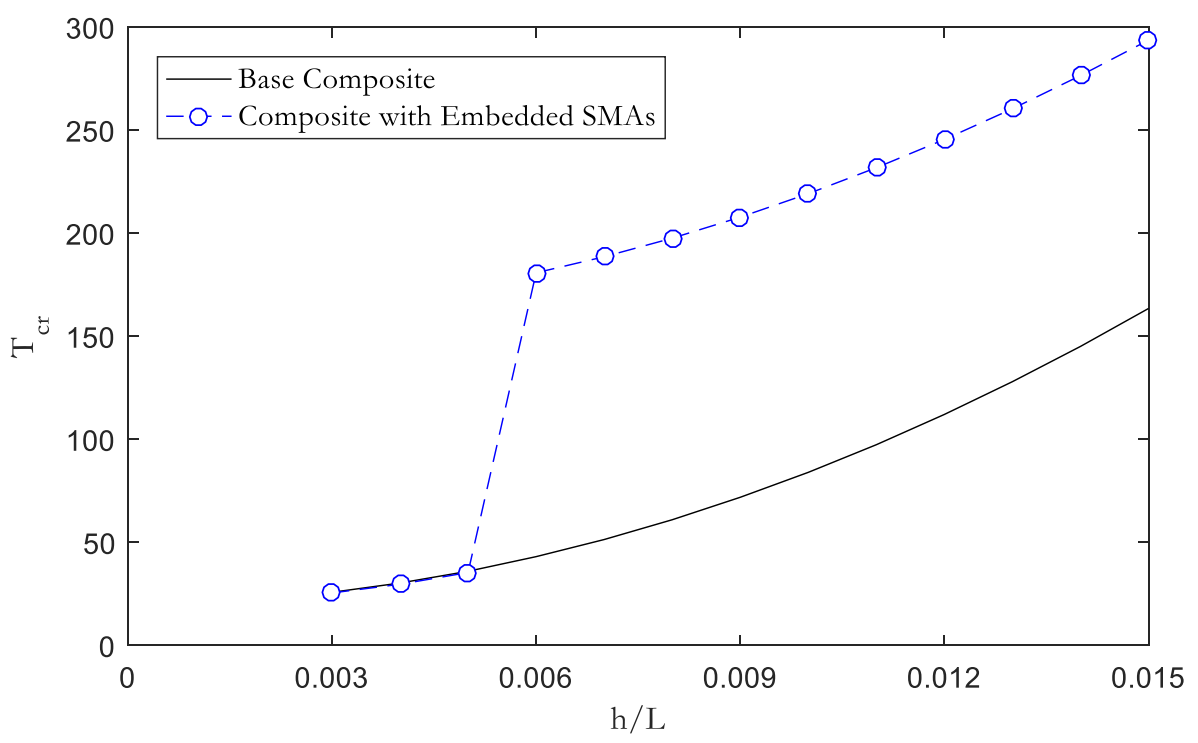

Fig 6 Influence of SMA wires on the critical buckling temperature of composite beams for various values of $h / L$ parameter

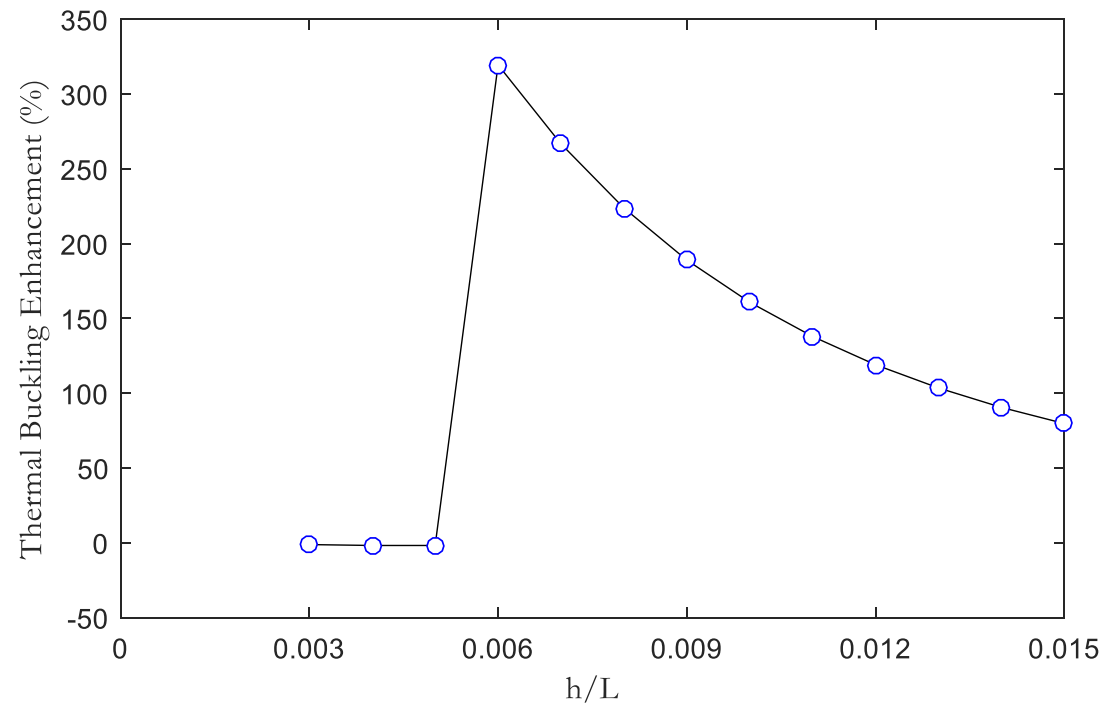

Fig 7 Enhancement of critical buckling temperature of composite beams due to the use of SMA wires for various values of $h / L$ parameter 


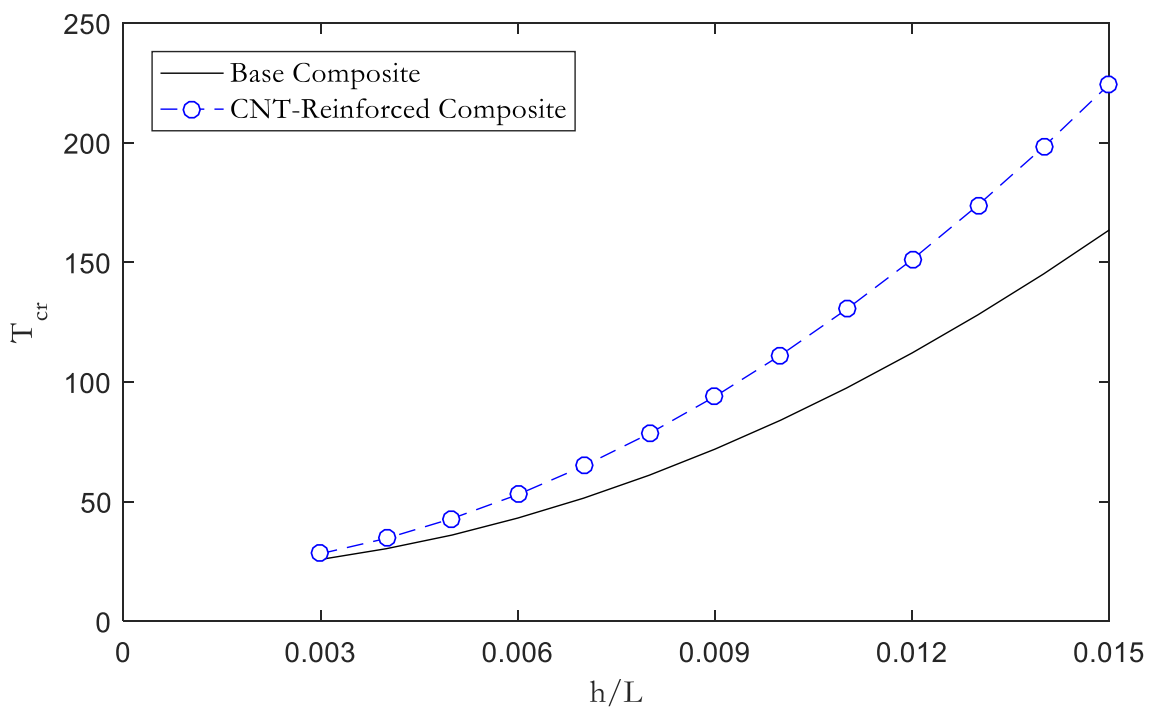

Fig 8 Influence of CNTs on critical buckling temperature of composite beams for various values of $h / L$ parameter

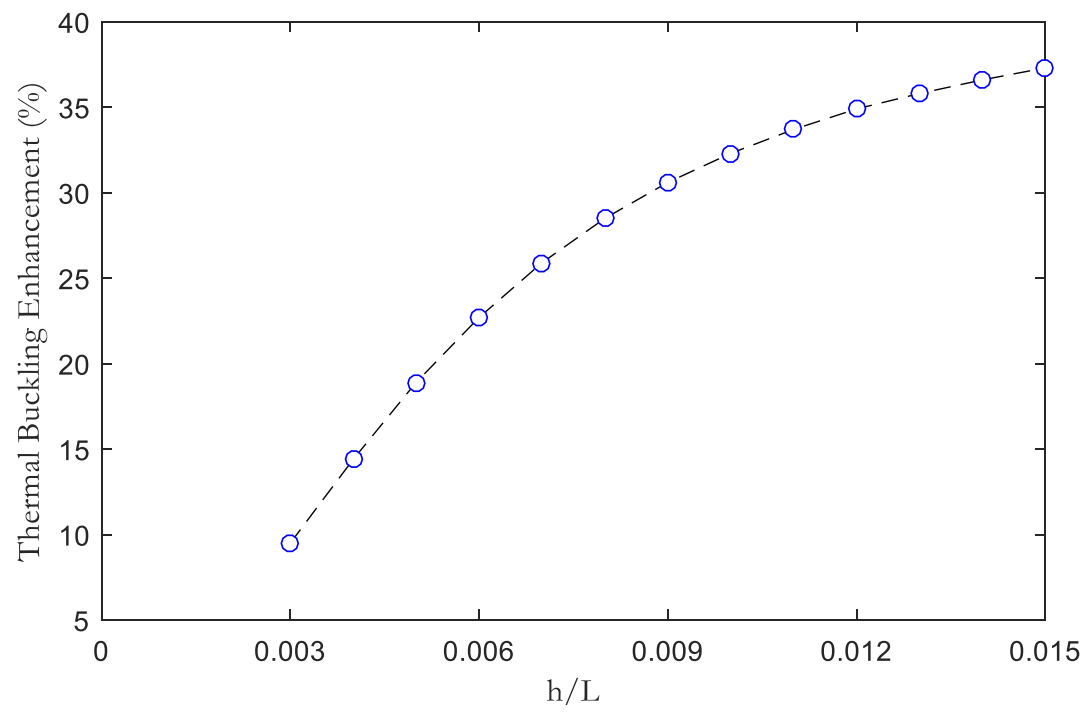

Fig 9 Improvement of critical buckling temperature of composite beams due to using CNTs for various values of $h / L$ 


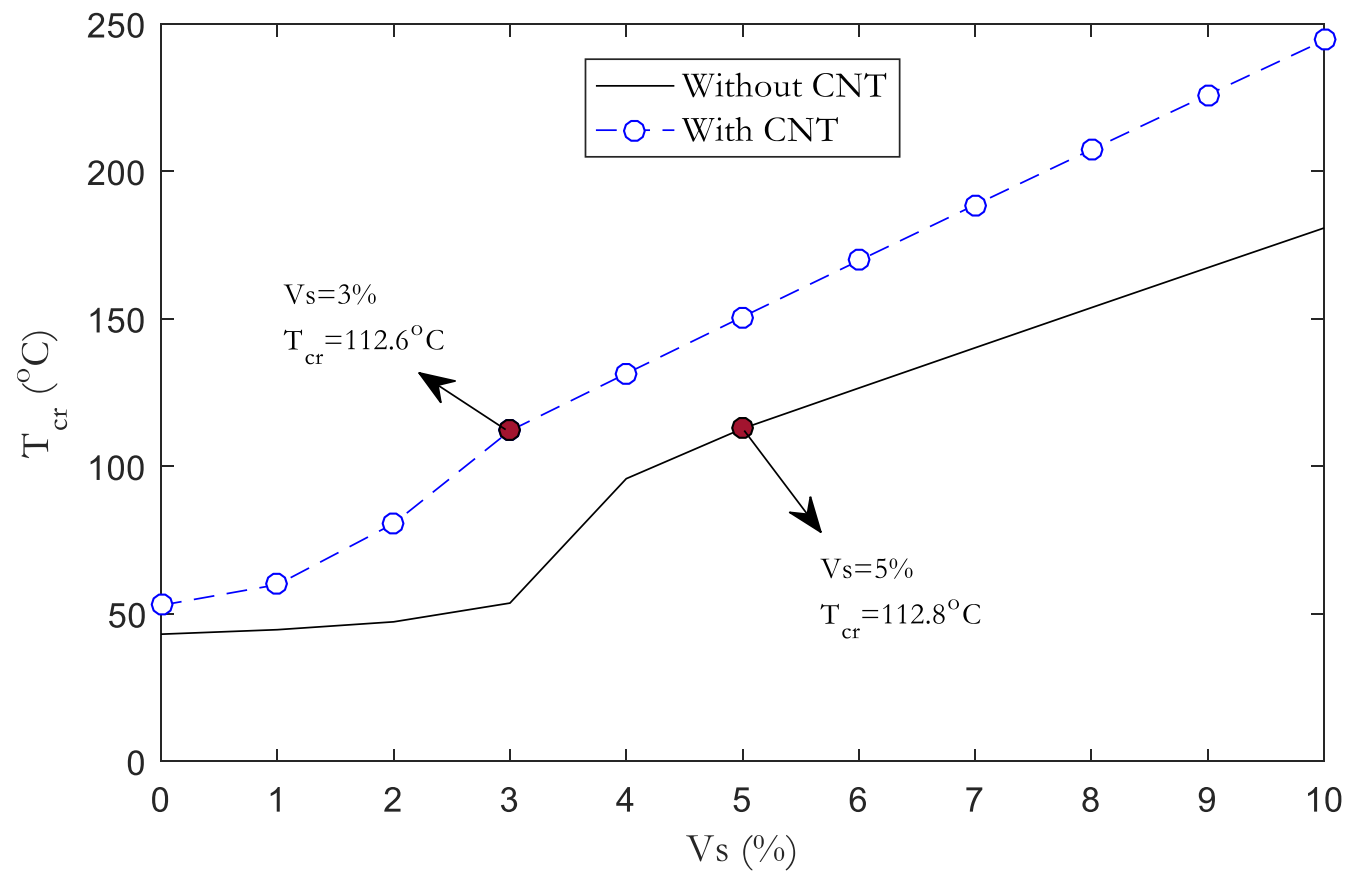

Fig 10 The role of CNTs in decreasing the required SMA volume fraction thermal buckling of composite beams $(h / L=0.006)$ 
Table 1 Material properties of epoxy

\begin{tabular}{llll}
\hline Property & Unit & Value & Method of obtaining \\
\hline Young modulus & $G P a$ & 3.10 & Data sheet \\
Poisson's ratio & - & 0.35 & Data sheet \\
Glass transition temperature & ${ }^{\circ} \mathrm{C}$ & 113 & Experiment (DMTA) \\
CTE & $1 /{ }^{\circ} \mathrm{C}$ & $66 \times 10^{-6}$ & Experiment (TMA) \\
\hline
\end{tabular}

Table 2 Material properties of long graphite fibers

\begin{tabular}{lll}
\hline Property & Unit & Value \\
\hline Axial Elastic Modulus & $G P a$ & 213.13 \\
Transverse Elastic Modulus & $G P a$ & 23.11 \\
Shear Modulus & $G P a$ & 8.97 \\
Axial Coefficient of Thermal Expansion & $1 /{ }^{\circ} \mathrm{C}$ & $-0.54 \times 10^{-6}$ \\
Transverse Coefficient of Thermal Expansion & $1 /{ }^{\circ} \mathrm{C}$ & $10.08 \times 10^{-6}$ \\
Poisson's ratio & - & 0.2 \\
\hline
\end{tabular}

Table 3 Material properties of the base composite (graphite/ epoxy)

\begin{tabular}{lll}
\hline Property & Unit & Value \\
\hline Longitudinal Elastic Modulus & $G P a$ & 129.62 \\
Transverse Elastic Modulus & $G P a$ & 7.23 \\
Shear Modulus & $G P a$ & 2.71 \\
Longitudinal Coefficient of Thermal Expansion & $1 /{ }^{\circ} \mathrm{C}$ & $0.18 \times 10^{-6}$ \\
Transverse Coefficient of Thermal Expansion & $1 /{ }^{\circ} \mathrm{C}$ & $29.13 \times 10^{-6}$ \\
Poisson's ratio & - & 0.27 \\
\hline
\end{tabular}


Table 4 Material properties of SMA wires (Asadi et al. 2013b)

\begin{tabular}{llllc}
\hline $\begin{array}{l}\text { Transformation } \\
\text { temperatures }\end{array}$ & Moduli & $\begin{array}{l}\text { Phase diagram } \\
\text { parameters }\end{array}$ & Density, CTE & $\begin{array}{c}\text { Poisson's, } \\
\text { Maximum Residual } \\
\text { Strain }\end{array}$ \\
\hline$M_{f}=9^{\circ} \mathrm{C}$ & $E_{A}=67 \mathrm{GPa}$ & $C_{M}=8 \mathrm{MPa} /{ }^{\circ} \mathrm{C}$ & $\rho=6450 \mathrm{~kg} / \mathrm{m}^{3}$ & $v=0.33$ \\
$M_{s}=18.4^{\circ} \mathrm{C}$ & $E_{M}=26.3 \mathrm{GPa}$ & $C_{A}=13.8 \mathrm{MPa} /{ }^{\circ} \mathrm{C}$ & & $\varepsilon_{L}=0.067$ \\
$A_{s}=34.5^{\circ} \mathrm{C}$ & $\Theta=0.55 \mathrm{MPa} /{ }^{\circ} \mathrm{C}$ & $\sigma_{s}^{c r}=100 \mathrm{MPa}$ & $\alpha_{s}=10.26 \times 10^{-6} /{ }^{\circ} \mathrm{C}$ & \\
$A_{f}=49^{\circ} \mathrm{C}$ & & $\sigma_{f}^{c r}=170 \mathrm{MPa}$ & & \\
\hline
\end{tabular}

Table 5 Material properties of MWCNTs

\begin{tabular}{lll}
\hline Property & Unit & Value \\
\hline Purity & - & $95 \%$ \\
Outer diameter & $n m$ & $20-30$ \\
Inner diameter & $n m$ & $5-10$ \\
Tube length range & $m m$ & $10-30$ \\
Specific surface area & $m^{2} / g r$ & 110 \\
\hline
\end{tabular}

Table 6 Material properties of $0.3 \mathrm{wt} \%$ CNT-reinforced epoxy polymer

\begin{tabular}{llll}
\hline Property & Unit & Value & Method of obtaining \\
\hline Young modulus & $G P a$ & 3.38 & Theoretical model \\
Poisson's ratio & - & 0.35 & Assumption \\
Glass transition temperature & ${ }^{\circ} \mathrm{C}$ & 110.5 & Experiment (DMTA) \\
$\mathrm{CTE}$ & $1 /{ }^{\circ} \mathrm{C}$ & $44 \times 10^{-6}$ & Experiment (TMA) \\
\hline
\end{tabular}


Table 7 Material properties of nanocomposite (graphite/CNT/epoxy) beam

\begin{tabular}{lll}
\hline Property & Unit & Value \\
\hline Longitudinal Elastic Modulus & $G P a$ & 129.74 \\
Transverse Elastic Modulus & $G P a$ & 7.71 \\
Shear Modulus & $G P a$ & 2.89 \\
Longitudinal Coefficient of Thermal Expansion & $1 /{ }^{\circ} \mathrm{C}$ & $-0.02 \times 10^{-6}$ \\
Transverse Coefficient of Thermal Expansion & $1 /{ }^{\circ} \mathrm{C}$ & $21.7 \times 10^{-6}$ \\
Poisson's ratio & - & 0.27 \\
\hline
\end{tabular}

Table 8 Non-dimensional critical buckling temperature of a three-layer $\left[0^{\circ} / 90^{\circ} / 0^{\circ}\right]$ composite beam for different $h / L$ ratio

\begin{tabular}{|c|c|c|c|c|}
\hline \multirow{2}{*}{$L / h$} & \multicolumn{4}{|l|}{$\overline{\Delta T}=\Delta T \frac{L^{2}}{h^{2} \alpha_{1}}$} \\
\hline & Present & Khdeir (2001) & $\begin{array}{c}\text { Emam and } \\
\text { Eltaher (2016) }\end{array}$ & Lee (1997) \\
\hline 10 & 0.8287 & 0.8281 & 0.8281 & 0.8236 \\
\hline 20 & 1.0214 & 1. 0212 & - & - \\
\hline 50 & 1.0926 & 1.0921 & 1.0925 & 1.0925 \\
\hline
\end{tabular}


Table 9 Non-dimensional thermal buckling load, $\bar{T}_{c r}=\Delta T_{c r}(L / h)^{2} / \alpha_{1}$, of composite beams with lamination scheme of $\left[0^{\circ} / 90^{\circ} / 0^{\circ}\right]$ and different material and geometrical properties

\begin{tabular}{|c|c|c|c|c|c|}
\hline \multirow{3}{*}{$\frac{E_{1}}{E_{2}}$} & \multirow{3}{*}{$\alpha_{1} / \alpha_{2}$} & \multicolumn{2}{|c|}{$\frac{L}{h}=10$} & \multicolumn{2}{|c|}{$\frac{L}{h}=50$} \\
\hline & & & Khdeir & & Khdeir \\
\hline & & FIESCIIt & (2001) & F ICSCEII & (2001) \\
\hline \multirow[t]{3}{*}{10} & 20 & 0.5104 & 0.5083 & 0.5923 & 0.5922 \\
\hline & 50 & 0.2916 & 0.2905 & 0.3385 & 0.3384 \\
\hline & 100 & 0.1701 & 0.1695 & 0.1974 & 0.1974 \\
\hline \multirow[t]{3}{*}{20} & 20 & 0.5939 & 0.5902 & 0.7830 & 0.7827 \\
\hline & 50 & 0.3959 & 0.3935 & 0.5220 & 0.5218 \\
\hline & 100 & 0.2545 & 0.2523 & 0.3356 & 0.3355 \\
\hline \multirow[t]{3}{*}{40} & 20 & 0.5691 & 0.5644 & 0.9264 & 0.9258 \\
\hline & 50 & 0.4378 & 0.4342 & 0.7126 & 0.7121 \\
\hline & 100 & 0.3162 & 0.3136 & 0.5147 & 0.5143 \\
\hline
\end{tabular}

Table 10 Effect of SMA volume fraction and pre-strain on critical buckling temperature of composite beams $(L / h=125)$

\begin{tabular}{|c|c|c|c|c|}
\hline \multirow{2}{*}{$\varepsilon_{0}$} & \multicolumn{4}{|l|}{$V^{s}$} \\
\hline & $0 \%$ & $5 \%$ & $10 \%$ & $20 \%$ \\
\hline $0 \%$ & 61.0 & 59.8 & 58.6 & 56.3 \\
\hline $1 \%$ & 61.0 & 130.2 & 197.6 & 327.6 \\
\hline $2 \%$ & 61.0 & 200.6 & 336.7 & 599.1 \\
\hline
\end{tabular}


Table 11 Effect of using both CNTs and SMA wires on critical buckling temperature of composite beams for different thickness to length ratios

\begin{tabular}{lcccc}
\hline & \multicolumn{2}{c}{$T_{c r}$} & & \\
\cline { 2 - 5 } & Base Composite & $\begin{array}{c}\text { SMA-reinforced } \\
\text { Composite }\end{array}$ & $\begin{array}{c}\text { CNT-reinforced } \\
\text { Composite }\end{array}$ & $\begin{array}{c}\text { CNT \& SMA- } \\
\text { reinforced Composite }\end{array}$ \\
\hline 0.003 & 25.8 & 25.5 & 28.2 & 27.7 \\
0.004 & 30.3 & 29.7 & 34.6 & 33.7 \\
0.005 & 36.0 & 35.4 & 42.9 & 235.1 \\
0.006 & 43.1 & 180.8 & 52.9 & 244.4 \\
0.007 & 51.4 & 188.6 & 64.8 & 255.3 \\
0.008 & 61.0 & 197.6 & 78.4 & 267.9 \\
0.009 & 71.9 & 207.8 & 93.9 & 282.2 \\
0.010 & 84.0 & 219.2 & 111.2 & 298.1 \\
0.011 & 97.4 & 231.8 & 130.3 & 315.7 \\
0.012 & 112.1 & 245.5 & 151.1 & 334.9 \\
0.013 & 128.0 & 260.4 & 173.8 & 355.8 \\
0.014 & 145.1 & 276.5 & 198.2 & 378.3 \\
0.015 & 163.5 & 293.7 & 224.4 & 402.4 \\
\hline
\end{tabular}

